\title{
Advection of the Salt Wedge and Evolution of the Internal Flow Structure in the Rotterdam Waterway
}

\author{
Michel A. J. DE NiJs AND Julie D. PiETRZAK \\ Environmental Fluid Mechanics Section, Delft University of Technology, Delft, Netherlands \\ JOHAN C. WINTERWERP \\ Environmental Fluid Mechanics Section, Delft University of Technology, and Deltares, Delft, Netherlands
}

(Manuscript received 28 January 2009, in final form 3 August 2010)

\begin{abstract}
An analysis of field measurements recorded over a tidal cycle in the Rotterdam Waterway is presented. These measurements are the first to elucidate the processes influencing the along-channel current structure and the excursion of the salt wedge in this estuary. The salt wedge structure remained stable throughout the measuring period. The velocity measurements indicate decoupling effects between the layers and that bedgenerated turbulence is confined below the pycnocline. The barotropic $M_{4}$ overtide structure is imposed at the mouth of the estuary, and the generation of $M_{4}$ overtides within the estuary is found to be relatively small. Internal tidal asymmetry does not make a significant contribution to the $M_{4}$ velocity frequency band. Instead, the combination of barotropic and baroclinic forcing, in conjunction with the suppression of turbulence at the interface, provides the main explanation for the time dependence and mean structure of the flow in the Rotterdam Waterway. This gives rise to the observed differences in the length of the flood and ebb, in the magnitudes of the flood and ebb velocities, in the length of the slack water periods, and in the timing of the onset of slack water at the surface and near the bed. It results in the formation of distinct exchange flow profiles at the head of the salt wedge around slack water and the creation of maximal velocities at the pycnocline during flood. Advection governs the displacement and structure of the salt wedge since turbulent mixing is suppressed. The tidal displacement of the salt wedge controls the height of the pycnocline above the bed at a particular site. Hence, it controls the height to which bed-generated turbulence can protrude into the water column. Consequently, the authors find asymmetries in the structure of the internal flow, turbulent mixing, and bed stresses that are not related to classical internal tidal asymmetry.
\end{abstract}

\section{Introduction}

Estuaries are regions in which exchange between inland freshwater systems and marine environments takes place. In many estuaries the dominant components in the salt balance are export of salinity by the freshwater discharge and import by the gravitational flow, leading to salinity distributions that may take the form of a salt wedge. Partially mixed or stratified systems are often characterized by frontal zones, separating the less dense and fresher river waters from the more dense seawater. A distinct feature of many estuaries is an estuarine turbidity maximum (ETM), which often results from the

Corresponding author address: Michel A. J. de Nijs, Delft University of Technology, Environmental Fluid Mechanics Section, P.O. Box 5048, Stevinweg 1, 2600 GA, Delft, Netherlands. E-mail: m.a.j.denijs@tudelft.nl accumulation of sediment at the tip of the salt wedge. Hence, estuaries serve as sediment traps and consequently have an important impact on coastal ecosystems. Understanding the exchange mechanisms governing estuarine systems is therefore of great scientific value.

The dominant physical processes in an estuary are the residual circulation, tidal velocity and mixing asymmetry, and freshwater inflow. Since the pioneering work of Pritchard (1954), Hansen and Rattray (1965), and Chatwin (1976), the classical view of estuarine circulation is one of a time-mean residual circulation resulting from the competition between the baroclinic pressure gradient, river outflow, and mixing. However, in reality an estuary is a very dynamic system. As pointed out by Geyer and Farmer (1989), various aspects of the dynamics preclude the use of tidally averaged equations.

Tide-induced variability in the density field and turbulent mixing requires that the mean estuarine properties 
must be understood as the tidal cycle average of the timedependent properties and their interaction. Jay (1991) and Jay and Smith (1990) sketched a dynamical picture suggesting that internal tidal asymmetry generates mean as well as overtide frequencies that affect the estuarine circulation in the Columbia River. Jay adopted the now classical term internal tidal asymmetry to distinguish between barotropic tidal asymmetry and an internal ebbflood asymmetry in the vertical profile of the horizontal current caused by the baroclinic pressure gradient and asymmetry in turbulent mixing between the flood and ebb. Therefore, velocity profiles exhibit more shear in the vertical on the ebb tide than on the flood tide. The term internal tidal asymmetry (Jay 1991; Jay and Musiak 1996) applies to the appearance of zero and overtide frequency components in the velocity field, which integrate to zero over the vertical. These components are the result of the tidally varying balance between the reversing barotropic and baroclinic pressure gradients and the tidally asymmetric turbulent mixing processes associated with asymmetries in stratification (Jay and Musiak 1996).

The theoretical analysis by Jay and Musiak (1994) showed that internal tidal asymmetry can maintain a salt and suspended particulate matter (SPM) balance against the seaward-directed freshwater discharge through velocity shear and salinity stratification correlations at zero and overtide frequencies. However, Jay and Musiak (1996) only investigated internal tidal asymmetry in the part of the estuary where saltwater was permanently present. They did not consider effects related to the advection of the salt wedge.

Advection is known to play a key role in the evolution of stratification. Simpson et al. (1990) showed the important role played by tidal straining in creating periodic stratification and mixing in many coastal seas and estuaries. They used the potential energy anomaly $(\phi)$ concept, defined by Simpson and Bowers (1981), to assess whether tide-induced turbulence can mix the vertical salinity structure. They demonstrated that differential advection by a vertical velocity shear acting upon a depthindependent horizontal density gradient can be used to explain the evolution of the stability of the water column. Moreover, at the other end of the spectrum in salt wedge estuaries, differential advection associated with exchange flows is also important.

It has been argued that asymmetric turbulent mixing processes can be induced by straining of the salinity field causing stronger stratification on the ebb tide than on the flood tide (e.g., Simpson et al. 1990; Geyer 1993) or unstable stratification on flood tide and stable stratification on ebb tide (e.g., Burchard and Baumert 1998). Tidal straining has been observed in a wide variety of estuarine and coastal systems, the Columbia River (Jay and Smith
1990), the York River estuary (Sharples et al. 1994), the Rhine region of freshwater influence (ROFI) (Simpson and Souza 1995), San Francisco Bay (Stacey et al. 1999), and the Hudson River (Nepf and Geyer 1996), among others. However, as we will show, the advection associated with displacements of a "frozen" longitudinal salinityinduced density structure is also an important mechanism.

In stably stratified fluids, a distinction can be made between processes with a diffusive character generated by stress at the bed and those generated at the interface by instabilities. Schijf and Schönfeld (1953) suggest that the latter can erode a salt wedge during ebb tide. Then, the velocity difference across the interface is larger than during flood, which results in more unstable internal wave modes. This intensifies mixing so that a brackish region develops between the near-bed saltwater and rather fresh water near the surface. Geyer and Farmer (1989) measured the collapse of a salt wedge structure in the Fraser estuary during ebb tide, which they ascribed to the aforementioned mechanism. Pietrzak et al. $(1990,1991)$ and Kranenburg et al. (1991) observed internal lee waves and resonant trapped internal waves in the Rotterdam Waterway and discussed their influence on turbulence production and mixing. A laboratory study by Kranenburg and Pietrzak (1989) of a turbulent two-layer fluid found that near the pycnocline there was a significant reduction in turbulence. They also demonstrated that, although internal waves can contribute to turbulence production in the lower layer, negligible mixing was observed between the layers.

Geyer et al. (2000) showed that the estuarine circulation in the Hudson River is controlled by the bed stress acting on the lower layer. They found that they could neglect the interfacial stress. Therefore, in the case of strong stratification it may be anticipated that the characteristic advection time scales are smaller than the turbulent diffusion time scales. Then, on a tidal time scale, advection-driven processes may govern the rate of change of the vertical density structure. Hence, an analysis of the growth of the pycnocline height along the estuary may be used to help determine which processes influence the evolution of the salt wedge structure.

Here we present a unique series of measurements recorded in the Rotterdam Waterway on 11 April 2006, as described in section 2. The observations are part of a broader study aimed at understanding the physical mechanisms involved in the formation of estuarine turbidity maxima and their role in the transport and deposition of sediment within this system (M. A. J. de Nijs 2010, unpublished manuscript; de Nijs et al. 2008, 2009, 2010). This paper explores the physical mechanisms controlling the internal flow structure along the Rotterdam Waterway. In section 3 we examine the role of tidal asymmetry and 
demonstrate that barotropic tidal asymmetry, remotely generated and imposed at the mouth, forces a time scale on the advection of the salt wedge. In section 4 we adopt ideas, first proposed by Geyer (1993), to derive a new mechanism that accounts for the evolution of the internal flow structure. In subsequent papers, we apply this mechanism to the entrapment of SPM (de Nijs et al. 2010).

\section{Methods}

\section{a. Survey setup and hydrodynamic conditions}

The lower river branches of the rivers Rhine and Meuse form the so-called Rhine-Meuse estuary, Fig. 1. A 13-h boat survey was carried out on 11 April 2006 prior to the spring full moon on 13 April. Rhine discharges varied from $5800 \mathrm{~m}^{3} \mathrm{~s}^{-1}$ at the beginning of April to about $4000 \mathrm{~m}^{3} \mathrm{~s}^{-1}$ on the day of the survey. Mean water level changes preceding and during this survey were smaller than about $0.30 \mathrm{~m}$. This survey included eight measuring stations (Fig. 1b). The stations were set up to characterize the (internal) tidal velocity, salinity, and sediment concentration field along the longitudinal axis of the Rotterdam Waterway. Measurements made at three stations (see Fig. 1b, stations 1, 6, and 7) were at the boundaries of our domain. This was done to quantify the physical mechanisms contributing to mass transport and to determine the ETM formation time scale. One vessel (Fig. 1b, station 8) recorded data while following the head of the salt wedge throughout the survey period. At stations 1, 2,6 , and 7 profiles of salinity and turbidity were taken at three points in velocity measurement transects perpendicular to the channel axis; the location coordinates are listed in Table 1. A complete cycle consisted of a velocity measurement transect and three profile measuring points. These cycles have been continuously carried out. A similar setup has been adopted at stations 3, 4, and 5 with one vessel. It profiled at these stations at two, one, and two points, respectively. In this paper, the data obtained at the points in the middle of the channels are shown (Table 2). The corresponding sediment data, including a description of the ETM dynamics, are presented in de Nijs et al. (2010).

\section{b. Instruments and procedures}

\section{1) CONVEnTIONAL CTD AND TURBIDITY INSTRUMENTS AND PROFILING PROCEDURES}

Optical backscatter-3 (OBS-3) and OBS-3A were used to measure turbidity profiles (optical backscatter). The OBS-3A combines an OBS probe with conductivity, temperature and pressure sensors. OBS-3 probes were mounted on frames with Falmouth Scientific Inc. (FSI) conductivity-temperature (CT) probes and pressure sensors at the same level. The OBS-3A operated with a maximal frequency response of $2 \mathrm{~Hz}$, while the OBS-3 and FSI CT probes had a maximal frequency response of $1 \mathrm{~Hz}$.

A routine of profiling was employed where the sensors moved through the water column while data was continuously logged. Different speeds of the instrument frames winches have been used over the water column to properly profile the near-bed region where large salinity and SPM gradients occur. During some surveys instrument packages were lowered by hand: from the free surface, $z=$ 0 , to $z=-50 \%$ of the total water depth $H$ the profiling speed was $0.5 \mathrm{~m} \mathrm{~s}^{-1}$, from $z=-0.5 H$ to $-0.8 H$ a few decimeters per second, and from $-0.9 H$ to the bed $-H$ a few centimeters per second. The recording ended when the bed was reached (criterion: pressure did not increase). The time to complete a downcast amounted to about 90-100 s.

Instrumentation and measurements at the transect locations are listed in Table 2 . Weights were attached to the instrument frames to prevent large deviations from the vertical due to drag by currents. At location 6 (Fig. 2, Table 2, it was possible to attach these weights above the instruments. However, at other locations the weights were too large to permit such a setup. As a result, the near-bed region and harbor bed may not have been completely profiled and/or properly detected.

\section{2) BOAT-MOUNTED ADCP VELOCITY MEASUREMENTS}

Velocity measurements were collected with broadbandtype, boat-mounted, $1200-\mathrm{kHz}$ Rowe Deines (RD) acoustic Doppler current profilers (ADCPs). The main velocity field has been determined while navigating along transects perpendicular to the channel axis. The measured quantities have been short-time and volume averaged. The following settings were applied for underway measurements: mode 1 , an ensemble time of $5 \mathrm{~s}, 15$ water pings, and a depth cell size of $0.5 \mathrm{~m}$.

Information on heading and speed were obtained from the ship's gyrocompass and ADCP bottom tracking. The gyro readings were corrected by a constant offset (e.g., Joyce 1989). The instrument noise level is estimated to be about $0.045 \mathrm{~m} \mathrm{~s}^{-1}$. The start and end points of ADCP transects were chosen some distance from the profiling points to reduce the effects of gyrocompass errors due to (Schuler) oscillations (Pollard and Read 1989) on measured velocities at the profiling points.

\section{c. Data processing}

\section{1) StRATIFICATION}

Gradient and bulk Richardson numbers were calculated. The gradient Richardson number is defined as 


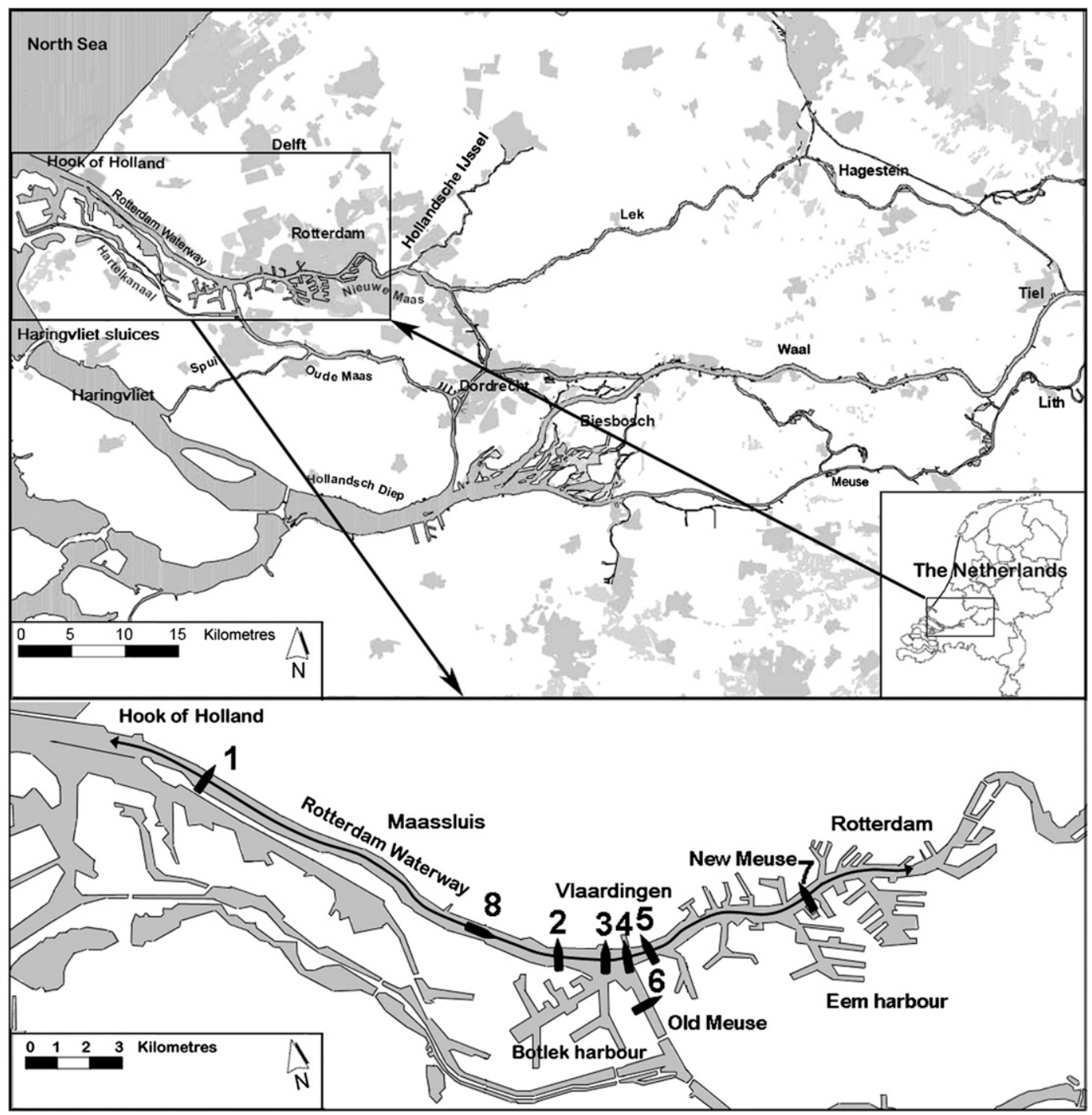

FIG. 1. (top) The Rhine-Meuse estuary and (bottom) the Port of Rotterdam (including the Rotterdam Waterway, New Meuse, and Old Meuse). The upestuary borders, where tides are not present, are located at approximately the cities Hagestein, Tiel, and Lith, located along the rivers Lek, Waal, and Meuse. The downestuary borders are at Hook of Holland and at the Haringvliet sluices, which form open and regulated connections to the North Sea, respectively. The Port of Rotterdam is part of this estuarine system. In general, the bathymetry and geometry of the various river branches change gradually along the longitudinal axis. The cross sections are approximately rectangular. Farther upestuary a distinction can be made between the main channel and the floodplain; hence a part of the cross section contributes to storage of water. Downestuary and in the middle part of the estuary, harbors and cutoff river branches contribute to storage of water. The locations of the seven stations are given in the map below. The stations were set up to characterize the tidal velocity and salinity field along the longitudinal axis of the Rotterdam Waterway. The seven stations include station 1, sites where saltwater is permanently present; stations 2-6, where saltwater is present during only a part of the tidal cycle; and station 7, which was always in the freshwater region during the survey. This setup was designed to allow one to distinguish between advection and local processes and to examine the processes that control the structure of the salt wedge during tidal excursions.

$$
\mathrm{Ri}_{g}=-\frac{g}{\rho} \frac{\partial \rho / \partial z}{(\partial u / \partial z)^{2}}
$$

where $g$ is the gravitational acceleration, $u$ the along-channel or primary velocity component, and $\rho$ the density of the water; when $\mathrm{Ri}_{g}>0.25$, the water column is considered stable (Miles 1961). The density and velocity differences have been calculated at $\sim 0.20 \mathrm{~m}$ intervals from the surface and to the bed. 
TABLE 1. Parisian coordinates of start (1) and end (2) points of ADCP transects and profiling points at B.

\begin{tabular}{cccr}
\hline & \multicolumn{3}{c}{ Coordinate points } \\
\cline { 2 - 4 } Transect & 1 & 2 & B \\
\hline 1 & $68978 \mathrm{E}, 442605 \mathrm{~N}$ & $69363 \mathrm{E}, 443094 \mathrm{~N}$ & $69200 \mathrm{E}, 442885 \mathrm{~N}$ \\
2 & $79548 \mathrm{E}, 434730 \mathrm{~N}$ & $79675 \mathrm{E}, 435105 \mathrm{~N}$ & $79605 \mathrm{E}, 434905 \mathrm{~N}$ \\
3 & $81122 \mathrm{E}, 434250 \mathrm{~N}$ & $81203 \mathrm{E}, 434847 \mathrm{~N}$ & $81141 \mathrm{E}, 434503 \mathrm{~N}$ \\
5 & $82000 \mathrm{E}, 434205 \mathrm{~N}$ & $82000 \mathrm{E}, 434724 \mathrm{~N}$ & $82000 \mathrm{E}, 434373 \mathrm{~N}$ \\
6 & $81725 \mathrm{E}, 433160 \mathrm{~N}$ & $82100 \mathrm{E}, 433231 \mathrm{~N}$ & $81923 \mathrm{E}, 433195 \mathrm{~N}$ \\
7 & $87634 \mathrm{E}, 434755 \mathrm{~N}$ & $87468 \mathrm{E}, 435188 \mathrm{~N}$ & $87544 \mathrm{E}, 434990 \mathrm{~N}$ \\
\hline
\end{tabular}

The bulk Richardson number is defined as

$$
\mathrm{Ri}_{B}=\frac{g}{\rho|(\partial \rho / \partial z)|_{\max }} \frac{(\Delta \rho)^{2}}{(\Delta u)^{2}},
$$

where $\Delta$ represents a difference across the thickness of the pycnocline expressed by $\Delta \rho /|(\partial \rho / \partial z)|_{\max }$. The maximum absolute density gradient has been obtained from polynomial fits to the density profiles. The density and velocity differences have been determined from the surface and near-bed densities and velocities averaged over the upper and lower $0.5 \mathrm{~m}$, respectively.

\section{2) TIDAL ASYMMETRY}

Principal component analysis (Emery and Thomson 2001) has been used to determine the principal axes and velocities along the direction of maximum and minimum variance. The first velocities are referred to as primary or along-channel velocity components, and the latter as secondary or traverse velocity components. The velocity data near the surface (blanking distance) and near the bed (sidelobe effects) have been reconstructed by block extrapolation and a power-law profile (van Veen 1938) based on the velocity found in the near surface and deepest profiling point, respectively.
Gross characteristics of the tidal velocity asymmetry, both external and internal, along the Rotterdam Waterway are examined by determining the onset of the ebb and flood periods (when $|u(z)| \approx 0 \mathrm{~m} \mathrm{~s}^{-1}$ ), the length of the ebb and flood periods, length of the slack water periods (when $|u(z)|<0.25 \mathrm{~m} \mathrm{~s}^{-1}$ ), and velocity magnitude (Table 3). A harmonic analysis (e.g., Godin 1972; Pugh 1987; Li 2002) has been applied to water level and velocity data to analyze the propagation of the tidal wave in more detail and to determine the contribution of internal (baroclinic) and external (barotropic) tidal asymmetry of the observed flow field. This involved the calculation of the dominant tidal properties; the phase differences; amplitude ratios; normalized overtide current amplitudes $\left[R=\left(M_{4 ; U} / M_{4 ; \zeta}\right)\left(M_{2 ; U} / M_{2 ; \zeta}\right)^{-1}\right.$, where $\zeta$ and $U$ denote water level and depth-averaged velocity amplitudes of the $M_{2}$ tide and $M_{4}$ tidal constituents; and local inertiainduced accelerations $\left[d u(d t)^{-1}\right]$. The latter are averages over the period when $|u(z)|<0.25 \mathrm{~m} \mathrm{~s}^{-1}$, taken near the surface and near the bed.

According to an idealized model by Jay (1991) and Jay and Musiak (1996), internal tidal asymmetry can be expected at locations where saltwater is permanently present. Indicators of this internal asymmetry are a $180^{\circ}$ phase shift over the depth of the phase of the $M_{4}$ velocity

TABLE 2. The measuring locations, measured flow quantities, and instruments. An Eulerian measuring style was chosen for all measuring locations except location 8 where a Lagrangian-type measuring style was adopted. $\mathrm{Kmr}=$ river kilometer (Netherlands); MEX $=$ optical sensor.

\begin{tabular}{|c|c|c|c|}
\hline Location & Quantities & Instruments & Vessels \\
\hline 1) $\mathrm{Kmr} 1028$ & $\begin{array}{l}\text { Main flow velocity, CTD, turbidity, } \\
\text { and water samples }\end{array}$ & $\begin{array}{l}\text { ADCP, CTD, OBS-3, and } \\
\text { pump sampler }\end{array}$ & Spirit \\
\hline 2) $\mathrm{Kmr} 1015$ & $\begin{array}{l}\text { Main flow velocity, CTD, turbidity, } \\
\text { and water samples }\end{array}$ & $\begin{array}{l}\text { ADCP, CTD, OBS-3A, and } \\
\text { pump sampler }\end{array}$ & Bokkegat \\
\hline $\begin{array}{l}\text { 3) Botlek 4) Junction } \\
\text { 5) New Meuse }\end{array}$ & $\begin{array}{l}\text { Main flow velocity, CTD, turbidity, } \\
\text { and density of fluid mud layers }\end{array}$ & ADCP and SiltProfiler & Schulpegat \\
\hline 6) Old Meuse & $\begin{array}{l}\text { Main flow velocity, CTD, turbidity, } \\
\text { and water samples }\end{array}$ & $\begin{array}{l}\text { ADCP, CTD, OBS-3A, and } \\
\text { pump sampler }\end{array}$ & Tender \\
\hline $\begin{array}{l}\text { 7) New Meuse } \\
\text { (Eem Harbor) }\end{array}$ & $\begin{array}{l}\text { Main flow velocity, CTD, } \\
\text { and turbidity }\end{array}$ & ADCP and OBS-3A & Griend \\
\hline 8) Dynamic & $\begin{array}{l}\text { Main flow velocity, CTD, turbidity, } \\
\text { and density of fluid mud layers }\end{array}$ & ADCP and SiltProfiler & Calandwerken \\
\hline $\begin{array}{l}\text { Turning circle Botlek } \\
\text { Harbor }\end{array}$ & $\begin{array}{l}\text { Turbulent flow properties, velocity, } \\
\text { CTD, and turbidity }\end{array}$ & ADCP, EMS, CTD, and MEX & Rig: anchored station \\
\hline
\end{tabular}



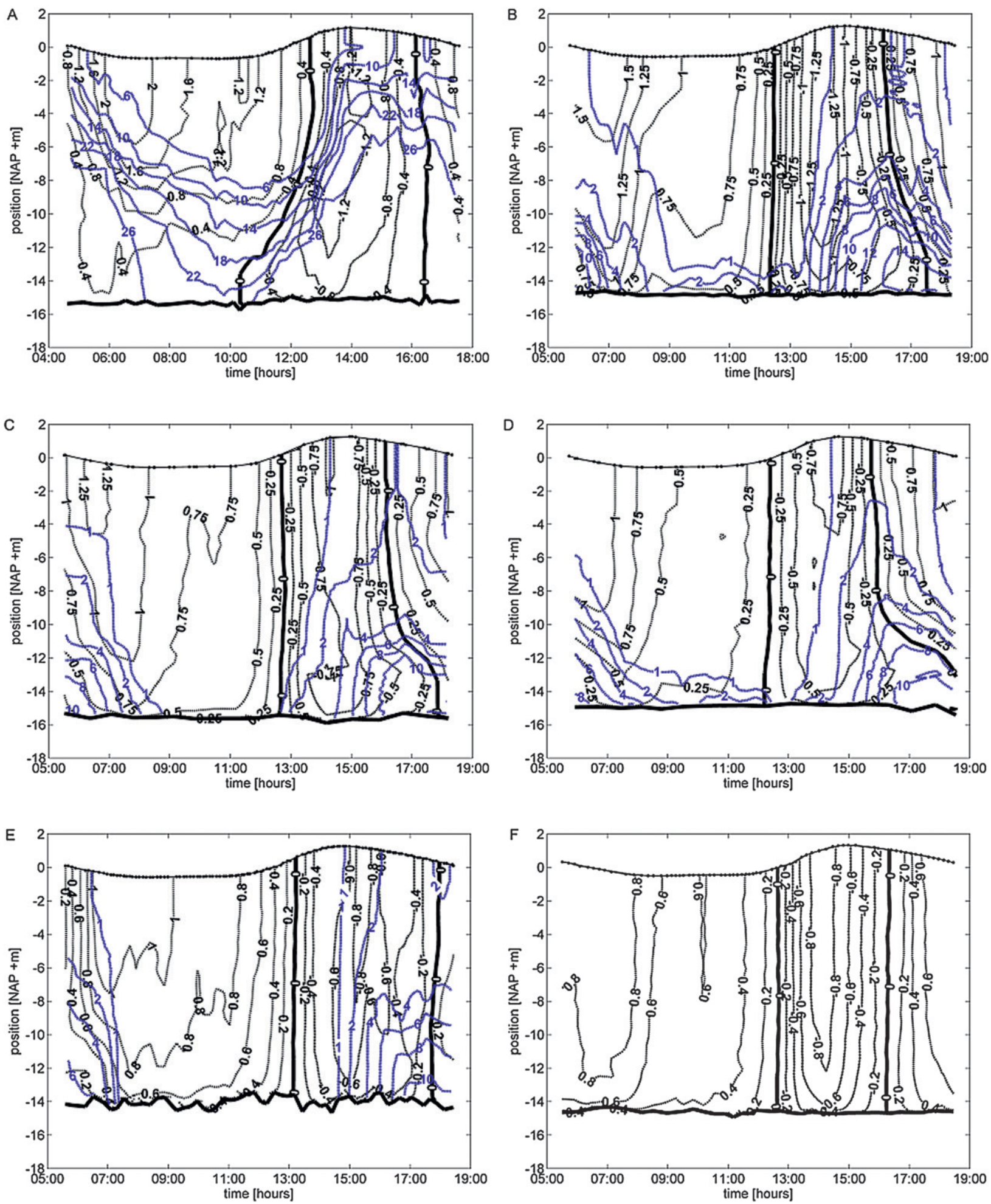

FIG. 2. Time series of vertical profiles of salinity (psu) and velocity $\left(\mathrm{m} \mathrm{s}^{-1}\right.$ ) recorded at stations (a) 1, (b) 2, (c) 3, (d) 5, (e) 6, and (f) 7 during the survey on 11 Apr 2006: the time of the survey is shown on the $x$ axis and position within the water column on the $y$ axis. The reference frame used in the Netherlands is the Normaal Amsterdamse Peil (NAP). The blue (black) contours depict salinity (velocity) with positive values indicating ebb. Saline water was present on both flood and ebb at station 1 , whereas station 7 was located outside the range of the salt wedge. At stations 2 to 6 , saline water was only present during part of the tidal cycle. Station 4 is not included as it is similar to stations 3 and 5. The landward limit of saltwater intrusion is defined here where salinity is 2 psu. The saltwater intrusion length is taken relative to Hook of Holland. The minimum (maximum) near-bed and near-surface saltwater intrusion lengths were $11 \mathrm{~km}(2 \mathrm{~km})$ at LWS and $20 \mathrm{~km}(13 \mathrm{~km})$ at HWS. 
TABLE 3. Tidal properties: each table cell has two entries, which depict from top to bottom values obtained near the surface and near the bed. The entries represent measured (internal) tidal properties: the onset of LWS and HWS (columns 2 and 3), the LWS and HWS period ( $T_{\mathrm{LWS}}$ and $T_{\mathrm{HWS}}$ in columns 4 and 5), the ebb and flood period ( $T_{\mathrm{EBB}}$ and $T_{\mathrm{FLOOD}}$ in columns 6 and 7 ), and peak ebb and flood velocities (columns 8 and 9). The maximum strength of the tidal currents can be estimated from linear wave theory, as $U=\zeta \cdot g^{1 / 2}(H)^{-1 / 2}$ valid for a long wave not affected by friction. With $\zeta=0.9 \mathrm{~m}$ and $H=16 \mathrm{~m}$, this gives $U=0.71 \mathrm{~m} \mathrm{~s}^{-1}$. The magnitude of the maximum ebb and flood tidal velocities exceed this estimate, which indicates the important effects of the geometry (tidal prism) on the tidal current strength.

\begin{tabular}{ccccccccc}
\hline \hline & LWS & HWS & $\begin{array}{c}T_{\text {LWS }} \\
(\mathrm{min})\end{array}$ & $\begin{array}{c}T_{\text {HWS }} \\
(\mathrm{min})\end{array}$ & $\begin{array}{c}T_{\text {EBB }} \\
(\mathrm{min})\end{array}$ & $\begin{array}{c}T_{\text {FLOOD }} \\
(\mathrm{min})\end{array}$ & $\begin{array}{c}\text { Peak ebb velocity } \\
\left(\mathrm{m} \mathrm{s}^{-1}\right)\end{array}$ & $\begin{array}{c}\text { Peak flood Velocity } \\
\left(\mathrm{m} \mathrm{s}^{-1}\right)\end{array}$ \\
\hline 1 & $12: 4510: 45$ & $16: 1516: 30$ & 40200 & 5080 & 535445 & 210300 & 2.10 .80 & 1.11 .2 \\
2 & $12: 3012: 30$ & $16: 1517: 30$ & 3030 & 4040 & 520465 & 225280 & 1.51 .1 & 1.31 .1 \\
3 & $12: 3012: 30$ & $16: 0017: 45$ & 4040 & 4060 & 535465 & 210380 & 1.20 .90 & 0.90 .9 \\
6 & $13: 1513: 15$ & $17: 4517: 45$ & 5060 & 4570 & 470470 & 275275 & 1.10 .7 & 0.750 .60 \\
5 & $12: 3012: 30$ & $15: 4518: 45$ & 6070 & 50120 & 520425 & 225320 & 1.10 .50 & 1.050 .60 \\
7 & $12: 4512: 45$ & $16: 3016: 30$ & 5050 & 6060 & 520520 & 225225 & 0.950 .80 & 0.800 .70 \\
\hline
\end{tabular}

component and values of the normalized overtide current amplitude $R$ larger than $1-2$.

\section{3) The Time EVolution of THE PYCNOCline HEIGHT}

We analyze the contribution of advection and turbulent mixing to the growth rate of the pycnocline height from the conservation equation of salt integrated over the pycnocline height. Density is controlled primarily by salinity within the estuary. A simplified along-channel conservation equation of density can be written as

$$
\frac{\partial \rho}{\partial t}+u \frac{\partial \rho}{\partial x}+\frac{\partial}{\partial z}\langle\rho w\rangle=0
$$

where $u$ is the along-channel or primary velocity component, $\rho$ the density of the water, and $\langle\rho w\rangle$ the turbulent buoyancy flux. Note that we quantify the vertical salt flux $\langle s w\rangle$ in terms of buoyancy flux and assume $\rho_{0}^{-1} g\langle\rho w\rangle \approx \rho_{0}^{-1} g\left\langle\gamma_{s} s w\right\rangle$ with $\gamma_{s}=0.72$. We estimate the buoyancy flux on the basis of gradient-type transport

$$
\langle\rho w\rangle=-\sigma_{T} \nu_{T} \frac{\partial \rho}{\partial z},
$$

where the turbulent viscosity $\nu_{T}$ has been determined following Geyer et al. (2000) and is presented in de Nijs et al. (2010). The Munk and Anderson (1948) relationship for the turbulent Prandtl-Schmidt number $\sigma_{T}$ has been used to convert turbulent viscosity to turbulence diffusivity. This relationship provided a reasonable fit to turbulence data obtained in Botlek Harbor (de Nijs 2010). Integration of Eq. (3) over the pycnocline height $\delta$ gives

$$
\int_{z=0}^{\delta} \frac{\partial \rho}{\partial t} d z+\int_{z=0}^{\delta} u \frac{\partial \rho}{\partial x} d z+\left.\langle\rho w\rangle\right|_{\text {pycnocline }}=0
$$

in which $\left.\langle\rho w\rangle\right|_{\text {pycnocline }}$ is the buoyancy flux at the pycnocline. Terms 1 and 3 have been obtained from data at stations 1 and 2 , and term 2 has been calculated from the transect measurements. The local rate of change term in the above equation is related to the growth of the pycnocline height above the bed. The second and third terms represent advection integrated over the pycnocline height and the vertical turbulent buoyancy flux at the top of the boundary layer at the pycnocline, respectively. The pycnocline position in the water column has been taken equal to the position of the maximal absolute vertical density gradient. It is noted that obvious outliers in terms of pycnocline height were removed manually. We also estimate a tidal and spatial mean buoyancy flux on the basis of a control volume method for time series measurements (MacDonald and HornerDevine 2008) to allow comparison with observations from the Fraser River estuary. The computed buoyancy flux is a weighted average of measurements at three profiling points in a cross section.

\section{4) ESTIMATION OF TERMS IN AN ALONG-CHANNEL MOMENTUM BALANCE}

Some terms in a simplified along-channel momentum balance are estimated. The data have been collected from successive passages through the head of the salt wedge. The purpose of this analysis is to quantify and determine the dominant terms. Note that these calculations are estimates only since proper ensemble averaging could not be applied. The following momentum balance, where only the along-channel terms have been retained, reads

$$
\begin{aligned}
\frac{\partial u}{\partial t} & +u \frac{\partial u}{\partial x}+g \frac{\partial \eta}{\partial x}+\int_{z=z^{*}}^{\eta} \frac{g}{\rho_{0}} \frac{\partial \rho}{\partial x} d z+\frac{\partial}{\partial x}\langle u u\rangle \\
+ & \frac{\partial}{\partial z}\langle u w\rangle=0
\end{aligned}
$$

where $u$ is the along-channel or primary velocity component, $\eta$ the water level, $\rho$ the density of water, $\rho_{0}$ the 
reference density of water, $\langle u u\rangle$ a normal Reynolds stress, and $\langle u w\rangle$ a Reynolds shear stress. The upestuary direction is taken as positive. Only terms 2 (advection), 3 (barotropic pressure gradient-induced acceleration), and 4 (baroclinic pressure gradient-induced acceleration) could be calculated from the data as we have no turbulence data. Term 3 has been calculated from fixed water level stations at Hook of Holland, Maassluis, Vlaardingen, and Rotterdam.

\section{Results}

\section{a. An Eulerian picture of the evolution of velocity and salinity}

\section{1) Along-CHANnel SAlinity AND Velocity DISTIBUTION FROM FIXED STATIONS}

The time series of velocity and salinity profiles (Fig. 2) show how the salt wedge retreats on the ebbing tide and then propagates back on the flooding tide. There is an asymmetry in the water level elevation with a much longer low water period and shorter high water period, Fig. 3. Note the effects of baroclinic shear flows, as a result of which velocity differences between the upper and lower part of the water column are larger on ebb than on flood. The tidal excursions of the salt wedge caused large variations in near-bed salinity and vertical stratification at station 1 . Note, however, that saline water was always present at this location. At stations 2-6, freshwater (0-3 psu) was present near the surface throughout the tidal cycle, suggesting that the salt wedge structure remained stable throughout the measurement period.

The salt wedge reaches the junction of the Old Meuse and New Meuse, after the first half of flood. It then bifurcated at the junction Rotterdam Waterway-Old Meuse-New Meuse. Exchange flow profiles were observed in the New Meuse at high water slack (HWS) (station 5) but did not occur in the Old Meuse (station

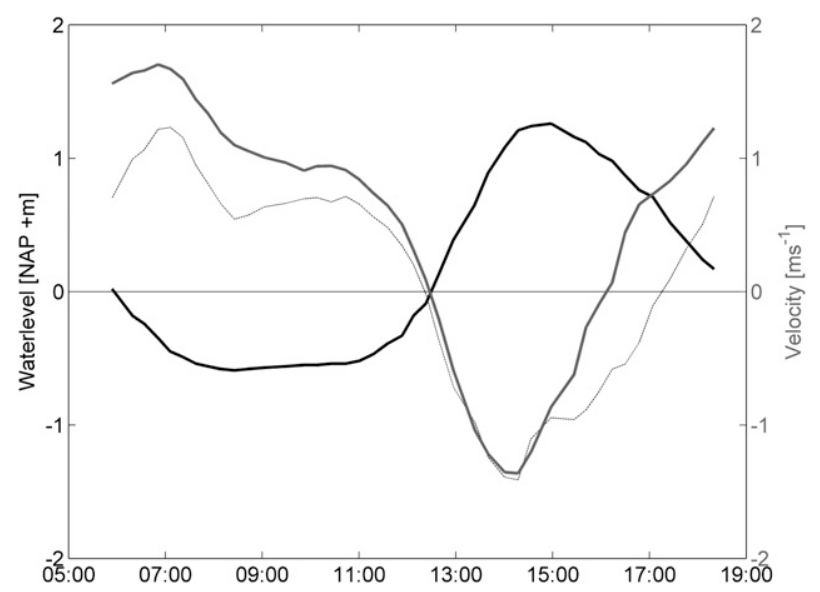

FIG. 3. Time series of water level (black line), velocity $2.5 \mathrm{~m}$ above bed (dashed gray line), and velocity $12.5 \mathrm{~m}$ above bed (thick gray line) at station 2 (Fig. 2b) during the survey on 11 Apr 2006. The reference frame used in the Netherlands is the Normaal Amsterdamse Peil (NAP).

6). In the New Meuse on the landward side of the salt wedge (station 7), ebb tide started earlier than in the Old Meuse (station 6). However, at the limits of saltwater intrusion, ebb tide in the Old Meuse (station 6) occurred earlier in the lower layer than in the New Meuse (station 5). This is ascribed to the larger opposing barotropic pressure gradients in the Old Meuse than in the New Meuse. The cross section of the New Meuse is smaller than the cross section of the Old Meuse, but its net discharge is larger. Hence, the phase differences between the onset of ebb in the New Meuse and Old Meuse also vary over the water column, Table 4 . This indicates that barotropic, as well as baroclinic, driven phase differences occur between the Old Meuse and New Meuse.

It should also be noted that the barotropic forcing in the Rotterdam Waterway is not perfectly cyclic owing to a diurnal inequality imposed at the mouth, with the

TABLE 4. Tidal properties obtained from harmonic analysis of water level and velocity records acquired on 11 Apr 2006 . Columns 2 and 3: phase differences, columns 5 and 6: amplitude ratios, column 7: normalized overtide current amplitudes $R=\left(M_{4 ; U} / M_{4 ; \zeta}\right)\left(M_{2 ; U} / M_{2 ; \zeta}\right)^{-1}$, and columns 8 and 9: local inertia-induced accelerations $(d u / d t)$. The latter are averages over the period when $|u(z)|<0.25 \mathrm{~m} \mathrm{~s}{ }^{-1}$ taken near the surface and near the bed. In the Rotterdam Waterway the barotropic tidal characteristics are a function of the forcing conditions and changing geometry and water distribution along the axis of the estuary. This is indicated by the dominance of the barotropic tide in the $M_{4 ; \zeta, U}$ frequency band near the mouth and in the down-estuary part of the Rotterdam Waterway (stations 1-3) and the nearly continuous along-channel distribution of the $M_{4}\left(M_{2}\right)^{-1}$ water level and current amplitude ratios.

\begin{tabular}{|c|c|c|c|c|c|c|c|c|}
\hline & $M_{2 ; \zeta}-M_{2 ; U}$ & $2 M_{2 ; \zeta}-M_{4 ; \zeta}$ & $2 M_{2 ; U}-M_{4 ; U}$ & $M_{4 ; \zeta} / M_{2 ; \zeta}(-)$ & $M_{4 ; U} / M_{2 ; U}(-)$ & $R(-)$ & $|d u / d t|_{\mathrm{LWS}}\left(\mathrm{m} \mathrm{s}^{-2}\right)$ & $|d u / d t|_{\text {HWs }}\left(\mathrm{m} \mathrm{s}^{-2}\right)$ \\
\hline 1 & $14^{\circ}$ & $13^{\circ}$ & $-23^{\circ}$ & 0.22 & 0.3 & 1.4 & $2.0 \times 10^{-4} 1.0 \times 10^{-4}$ & $3.0 \times 10^{-4} 1.4 \times 10^{-4}$ \\
\hline 2 & $33^{\circ}$ & $16^{\circ}$ & $-26^{\circ}$ & 0.21 & 0.37 & 1.7 & $2.2 \times 10^{-4} 2.2 \times 10^{-4}$ & $10^{-4} 2.6 \times 10^{-4}$ \\
\hline 3 & $26^{\circ}-29^{\circ}$ & $14^{\circ}$ & $-30^{\circ}$ & 0.21 & 0.32 & 1.5 & $1.7 \times 10^{-4} 1.3 \times 10^{-4}$ & $2.2 \times 10^{-4} 1.8 \times 10^{-4}$ \\
\hline 5 & $46^{\circ}-55^{\circ}$ & $14^{\circ}-18^{\circ}$ & $-55^{\circ} /-51^{\circ}$ & 0.21 & 0.37 & 1.7 & $1.8 \times 10^{-4} 1.0 \times 10^{-4}$ & $1.5 \times 10^{-4} 1.4 \times 10^{-4}$ \\
\hline 6 & $0^{\circ}-4^{\circ}$ & $16^{\circ}$ & $-18^{\circ}$ & 0.21 & 0.22 & 1.2 & $1.8 \times 10^{-4} 1.2 \times 10^{-4}$ & $1.8 \times 10^{-4} 1.6 \times 10^{-4}$ \\
\hline 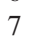 & $45^{\circ}$ & $20^{\circ}$ & $-32^{\circ}$ & 0.24 & 0.42 & 1.8 & $1.5 \times 10^{-4} 1.3 \times 10^{-4}$ & $1.9 \times 10^{-4} 1.6 \times 10^{-4}$ \\
\hline
\end{tabular}




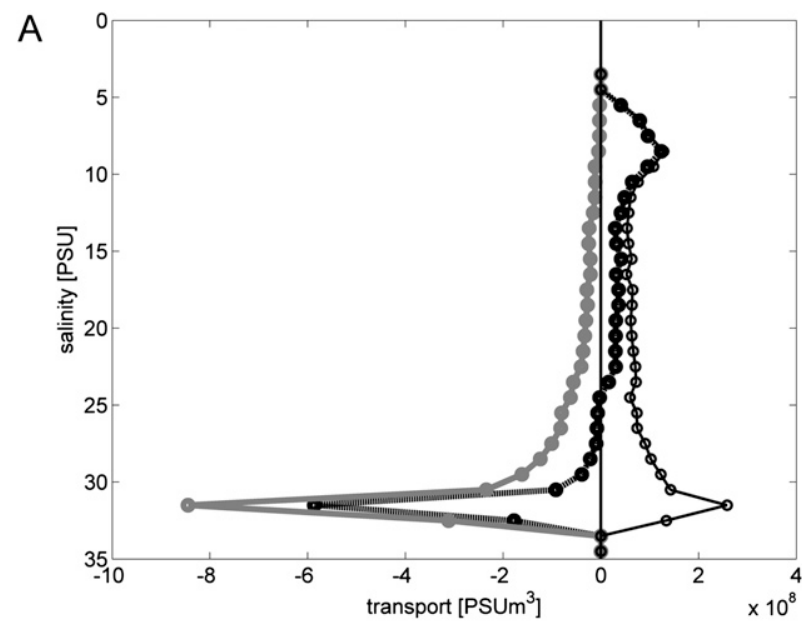

B

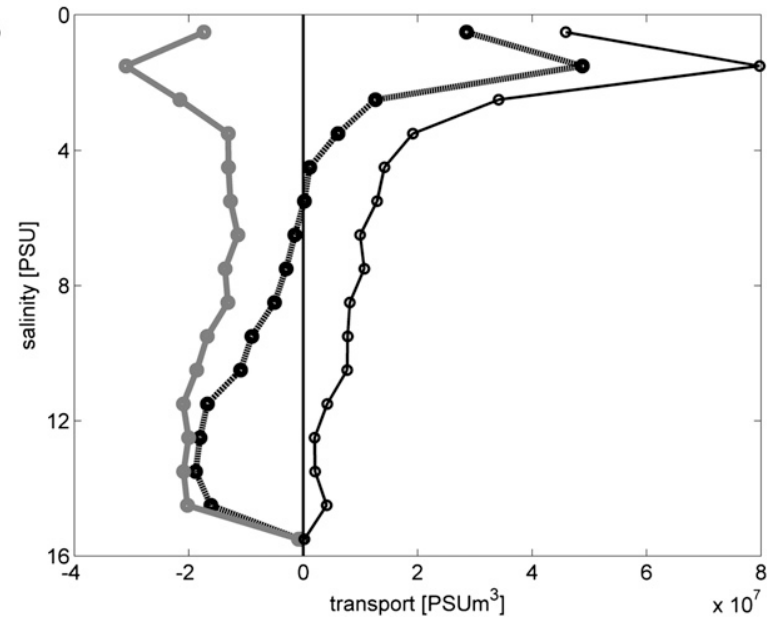

FIG. 4. The graphs show the salinity flux vs salinity bins at (a) station 1 and (b) station 2. The fluxes are based on the data collected at three profiling points in a cross section of the channel. The gray line, thin black line and thick black line represent flood transport (negative), ebb transport (positive), and residual transport, respectively.

result that the low water at the start of the survey was lower than the low water at the end of the survey. Hence, the excursion of the salt wedge is larger on flood than on ebb. As a result, a net import of salinity occurred over the semidiurnal tidal cycle associated with an asymmetric tidal displacement of the salt wedge because the ebb discharge at the end of the survey was smaller than the ebb discharge at the start.

Figure 4 shows tidal cycle-averaged salinity fluxes for a number of salinity bins at stations 1 and 2, where positive values represent seaward transport and negative values landward-directed transport. At both stations a net import of salinity occurred. Interestingly, the shape of the residual transport profile at station 1 is what one would expect on the basis of the competition between the freshwater discharge and the classical gravitational circulation driven by the along-channel baroclinic pressure gradient (Officer 1976). The residual transport profile at station 2 most likely is a combination of the competition between the baroclinic pressure-gradient-driven shear flows, asymmetry in tidal advection of the salt wedge, and the freshwater discharge. This is in agreement with the dispersive flux analysis presented in de Nijs et al. (2010). This analysis shows that the dominant terms in the dispersive flux balance at station 1 are advective transport associated with the freshwater discharge, gravitational circulation, and tidal oscillatory terms. At station 2 the dominant terms are associated with the freshwater discharge, tidal oscillatory terms, gravitational circulation, and baroclinic exchange flows driven by the along-channel pressure gradient.

Figure 4 indicates that salinity enters and exits the estuary at stations 1 and 2 along a similar range of salinities, but ebb transport generally occurs at lower salinities than flood transport. This is most likely due to an asymmetrical shift of the salt wedge and nonclosure of the water balance (see above) in combination with some dilution of incoming salinity waters farther upestuary. This dilution can be ascribed to turbulent mixing due to Kelvin-Helmholtz instabilities and velocity shear, as well as dispersion. It should be noted that the harbor basins provide temporary storage of saline waters during flood. This water is released at lower salinities, during a later stage of the ebb tide, near the bed (see Figs. $2 b$ and $2 \mathrm{~d}$ ), and thus appears to dilute the salt wedge. This implies that the salinity bins cannot be unambiguously interpreted as vertical coordinates.

The tidal and spatial averaged buoyancy fluxes at stations 1 and 2 amount to $2.2 \times 10^{-7} \mathrm{~m}^{2} \mathrm{~s}^{-3}$ and $1.3 \times$ $10^{-7} \mathrm{~m}^{2} \mathrm{~s}^{-3}$ on the basis of representative salt wedge lengths of 15 and $5 \mathrm{~km}$, respectively. These buoyancy flux values are one to two orders of magnitude lower than observed within the Fraser River estuary (MacDonald and Horner-Devine 2008), which suggests that the dilution of the salt wedge within a tidal excursion is much smaller in the Rotterdam Waterway than of the salt wedge in the Fraser River estuary.

\section{2) AlOng-CHANNEL SALINITY AND VELOCITY DISTIBUTION FROM TRANSECTS}

The tidal variation and displacement of the salt wedge are examined further from successive passages through the head of the salt wedge, Fig. 5, (transects 1 to 10). Transects 1-4 indicate ebb flow over almost the entire water column with strong shear between the upper and lower layers over the length of the salt wedge. Transects 3 and 4 record the beginning of the flood tide and the evolution of the exchange flow profiles, with small nearbed flood velocities seaward of Hook of Holland ( -1 to $0 \mathrm{~km})$. These profiles depict regions where near-bed 

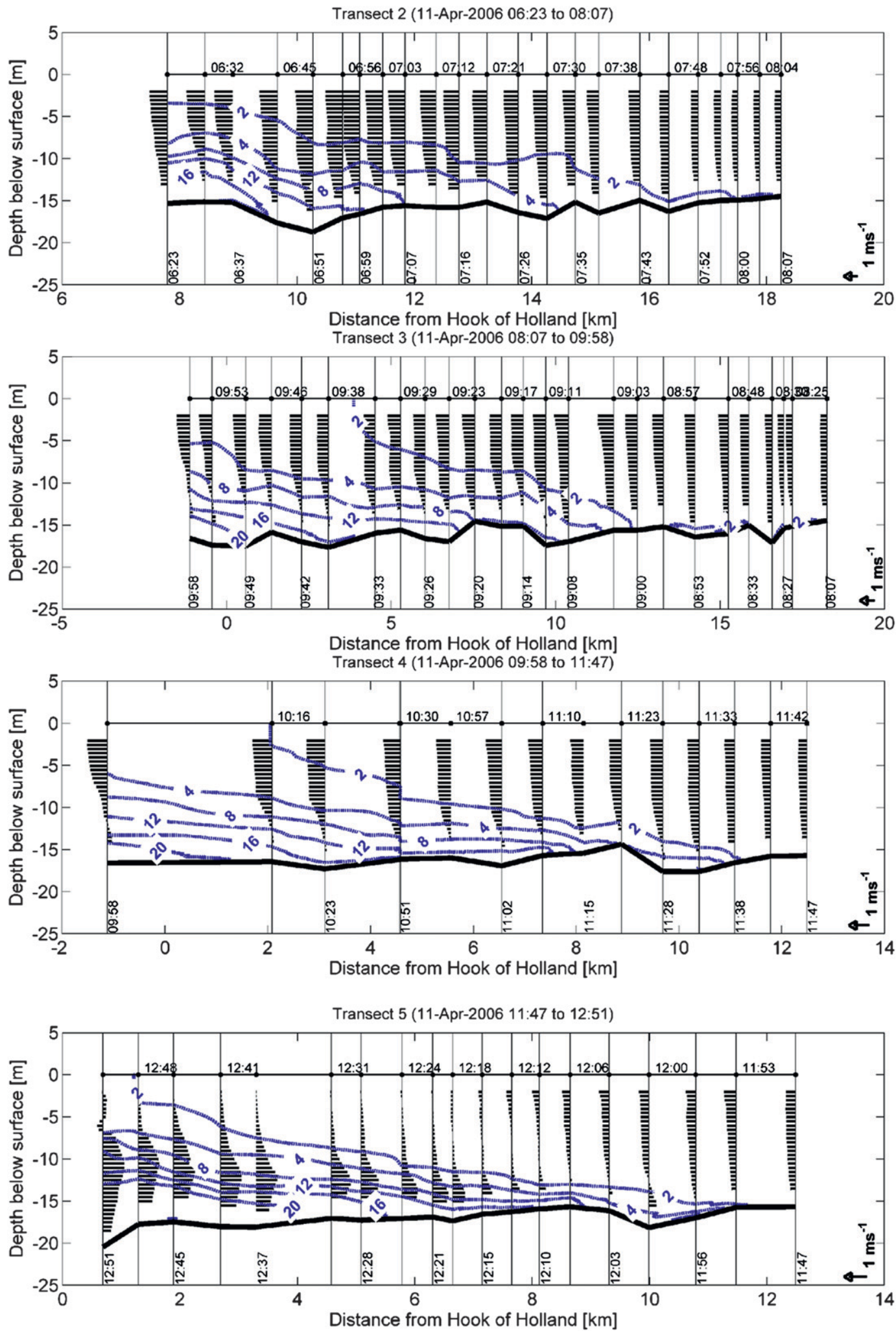

FIG. 5. Transects of the along-channel and vertical distribution of velocity $\left(\mathrm{m} \mathrm{s}^{-1}\right)$ and salinity (psu) recorded during 10 separate passages through the head of the salt wedge during the survey on 11 Apr 2006. Salinity contours are blue. Note the variations in velocity scale. 


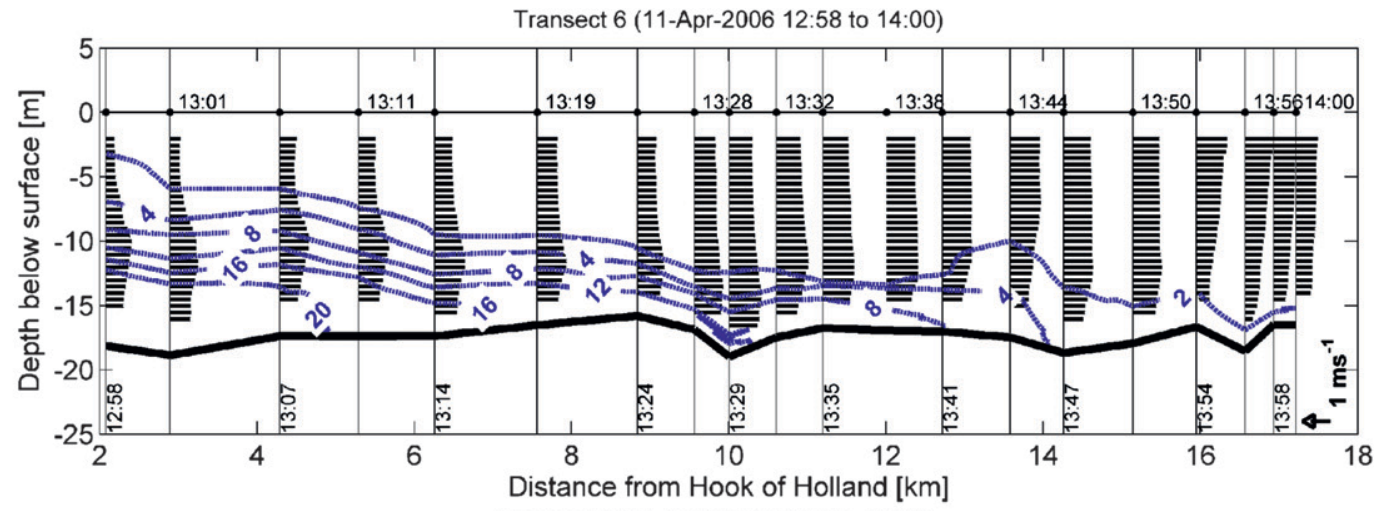

Transect 7 (11-Apr-2006 14:00 to 15:08)

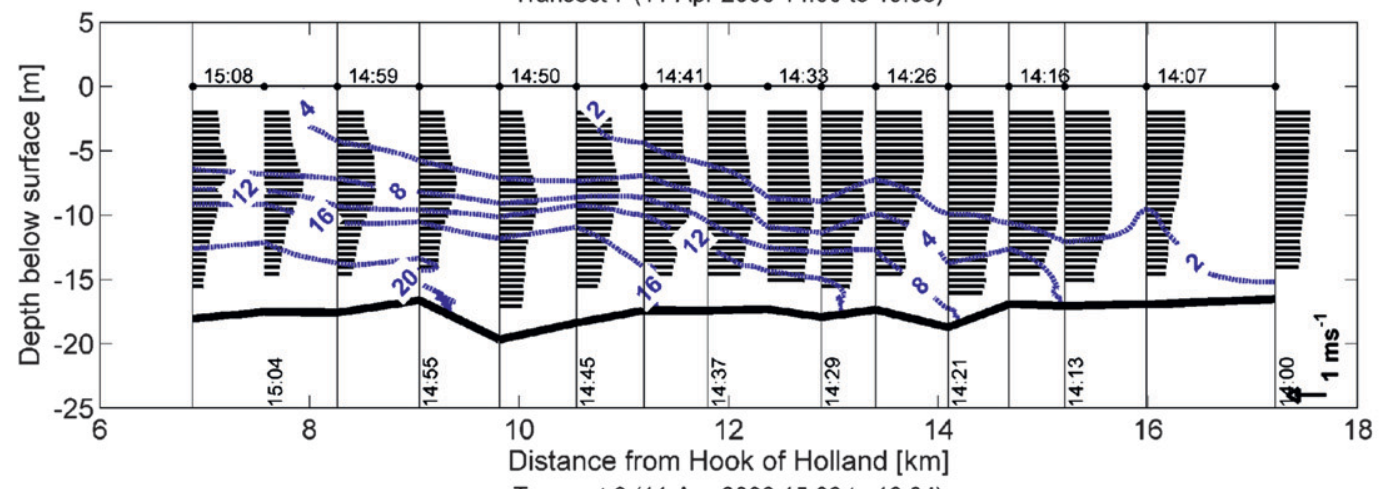

Transect 8 (11-Apr-2006 15:08 to 16:04)

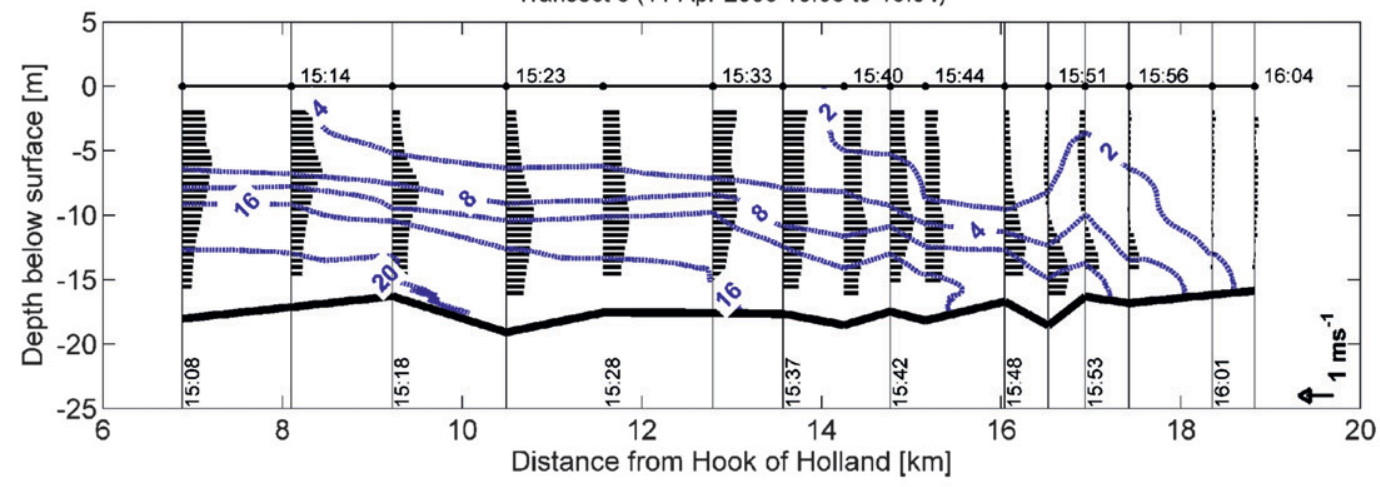

Transect 9 (11-Apr-2006 16:04 to 17:01)

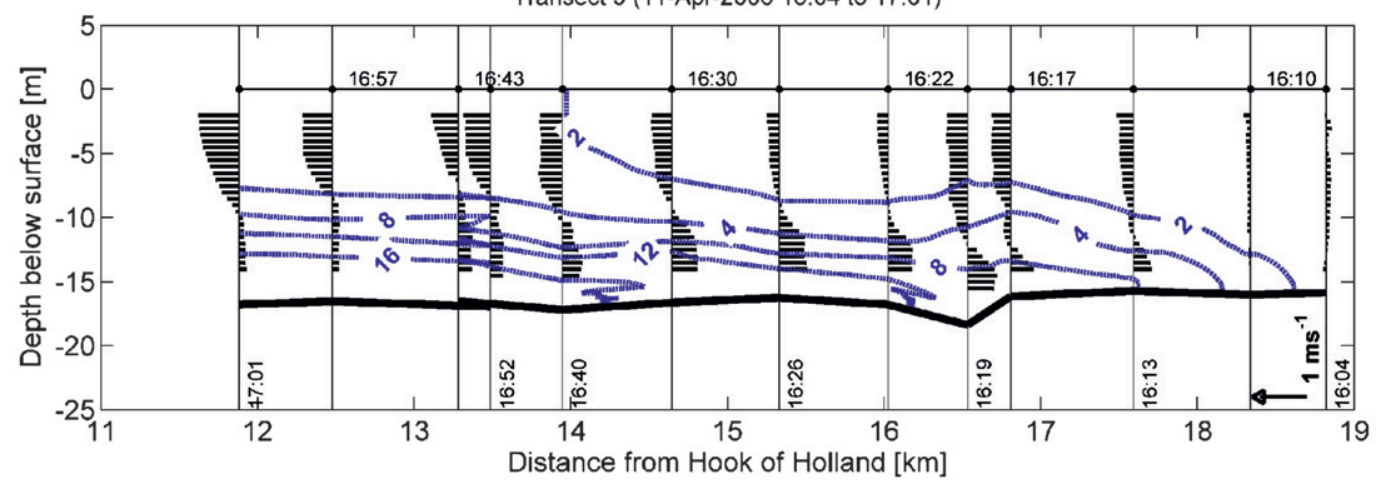

FIG. 5. (Continued) 

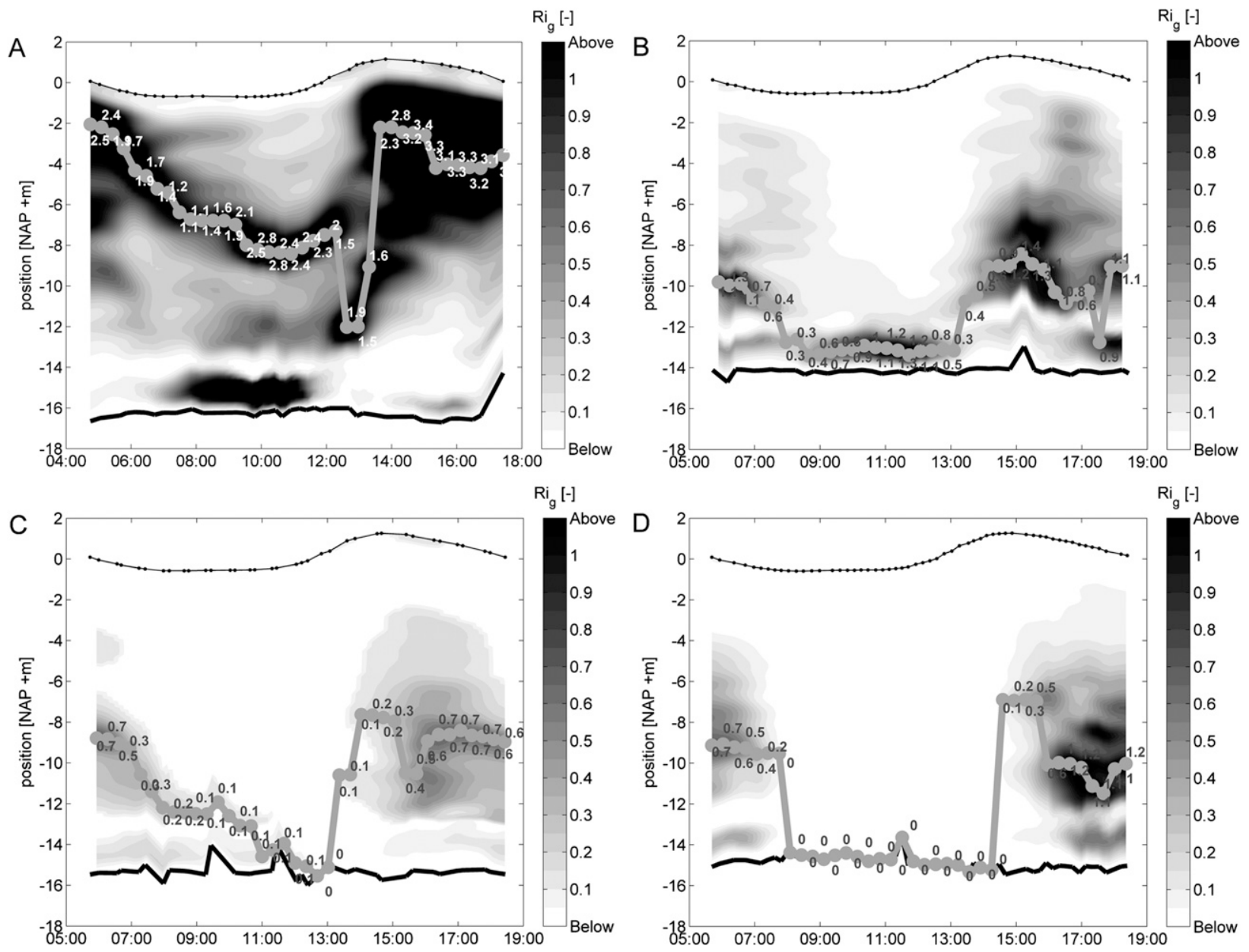

FIG. 6. Time series of vertical profiles of gradient Richardson number $\mathrm{Ri}_{g}$ recorded at stations (a) 1, (b) 2, (c) 5, and (d) 6 during the survey on 11 Apr 2006. The time of the survey is shown on the $x$ axis, and the position within the water column on the $y$ axis. The reference frame used in the Netherlands is the Normaal Amsterdamse Peil (NAP). The gray colors depict gradient Richardson numbers, and the gray line the position in the water column of maximum gradient Richardson number. The labels indicate the value of the maximum gradient Richardson number.

flows converge; on the landward side the flow near the bed is ebbing and on the seaward side it is flooding as a result of the baroclinic pressure gradient. These regions extend roughly from 0 to $4 \mathrm{~km}$ (transect 3 ) and from 2 to $7 \mathrm{~km}$ (transect 4 ) seaward of the head of the salt wedge. The slope of the 2 psu isohaline steepened (from transect 2 to 3 ); however, the slope of the 4 and 8 psu isohalines decreased (transects 2-4). This indicates a development toward a more layered salinity structure driven by differential advection as a result of which the 4 and 8 psu isohalines (transects 3 and 4) continue their gentle slope landward through the near-bed flow convergence regions. As the flood tide evolves, the vertical velocity structure exhibits a marked change, with a pronounced velocity maxima recorded at the pycnocline in transects 5-7. These jetlike features are dominant phenomena throughout the flood tide.
During the early evolution of the flood, transect 5 shows that the velocities near the bed are larger than those near the surface; these velocities are comparable at transect 6 . The landward decrease of near-surface and near-bed velocities recorded along transect 5 and the subsequent landward increase of the maximal velocities at the pycnocline observed in transect 6 explain the steepening of the isohalines from transect 4 to 5 and the subsequent flattening of the isohalines from transects 5 to 6 . Subsequently, by the time when transect 7 was conducted, flood velocities are generally higher in the upper part of the water column than near the bed, which explains the subsequent steepening of the isohalines observed from transect 6 to 7 .

The velocity maxima at the pycnocline advect water of intermediate salinity over saltier water toward regions of lower momentum and lower salinity. In the landward 

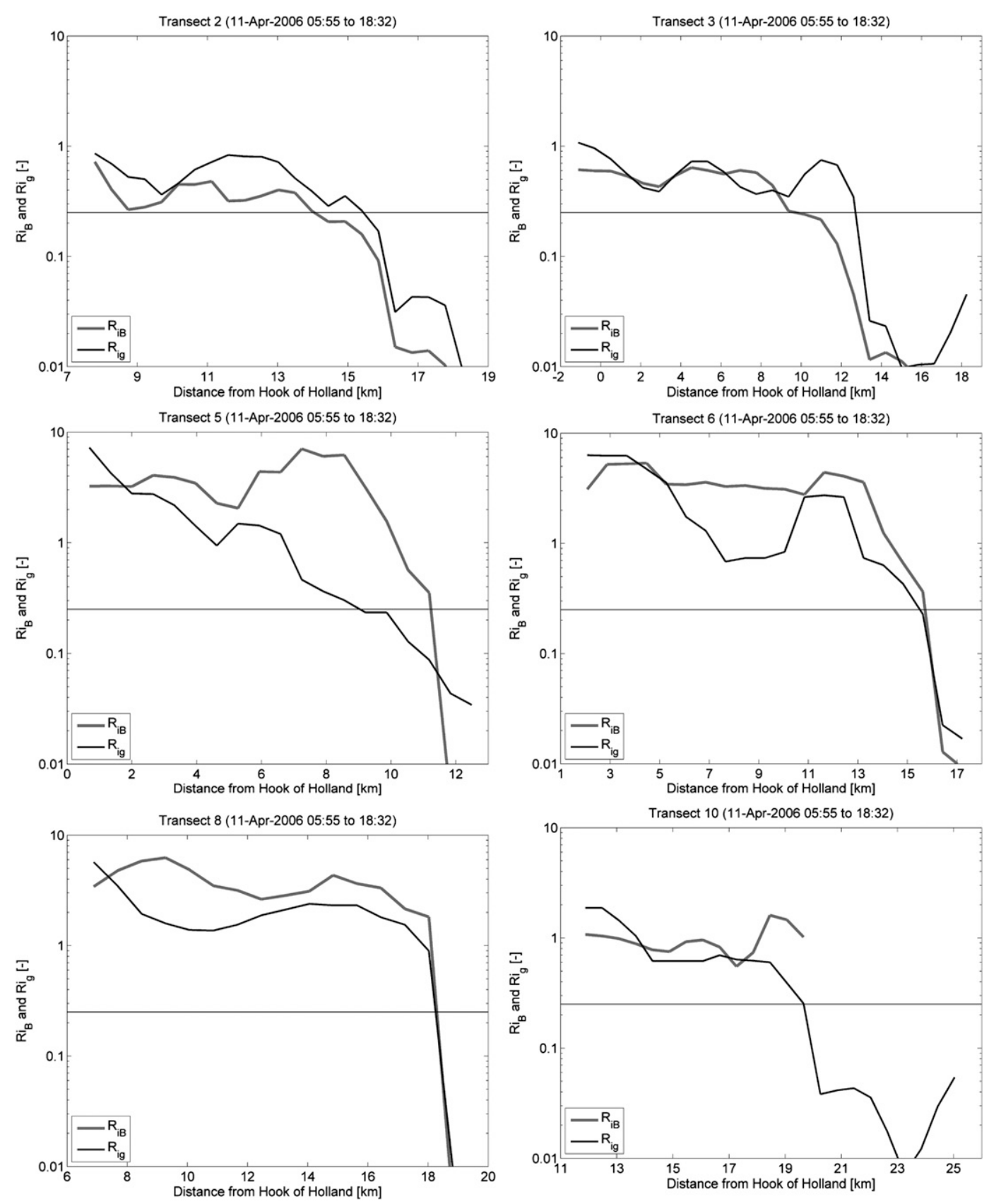

FIG. 7. Transects of the along-channel distribution of maximum gradient Richardson number $\left(\mathrm{Ri}_{g}\right.$, black line $)$ and bulk Richardson number $\left(\mathrm{Ri}_{B}\right.$, gray line) calculated from data from separate passages through the head of the salt wedge during the survey on 11 Apr 2006. Data for transects 2, 3, 5, 6, 8, and 10 are shown.

direction the velocities along the pycnocline decrease, which causes steepening of the isohalines. It is worth pointing out that the consequences of these advection processes may wrongly be interpreted as the result of turbulent mixing, as pointed out by Geyer and Farmer (1989). The isohalines (2, 4, and 8 psu) flattened from transects 8 to 10 as a result of exchange-type flow profiles. These exchange flows were observed at transect 8 from $16.5 \mathrm{~km}$ to the head and at transects 9 and 10 over the entire length of the salt wedge.

Advection-driven processes appear to control the temporal development of the salt wedge structure, that is, the displacements of the isohalines. This suggests that turbulent mixing is damped by stratification. This is in agreement with the gradient Richardson numbers, Figs. 6 and 7, and the observation from the transect measurements in 

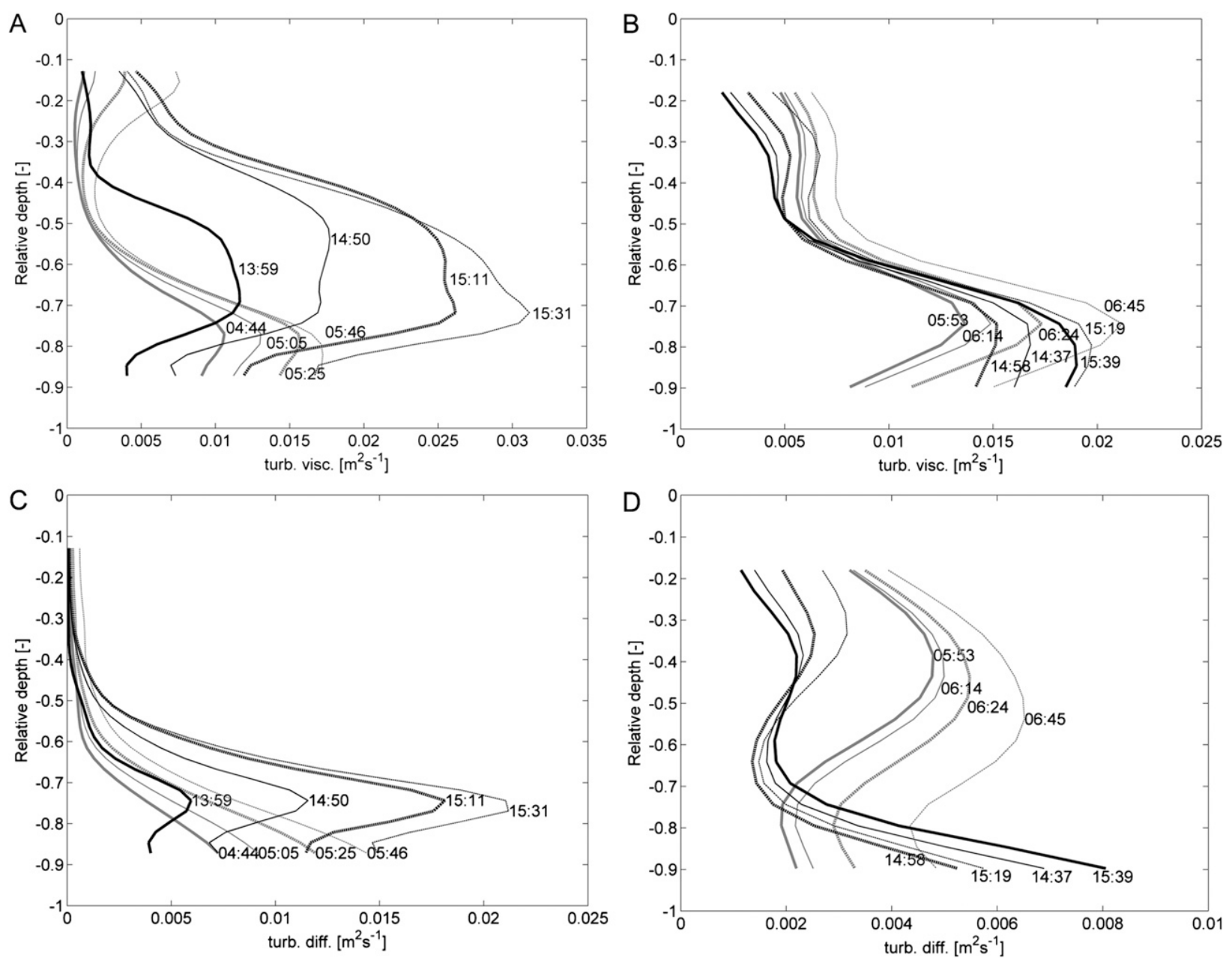

FIG. 8. Turbulent viscosity and diffusivity profiles at selected times during ebb and flood at stations (a),(c) 1 and (b),(d) 2 estimated from Reynolds shear stress profiles (de Nijs et al. 2010) and with the Munk and Anderson (1948) relationship for the turbulent Prandtl-Schmidt number.

Fig. 5, which show that the salt wedge remained stable throughout the tidal cycle. The gradient Richardson numbers (Fig. 6) and bulk Richardson numbers (not shown, see M. A. J. de Nijs 2010, unpublished manuscript) had values larger than 0.25 and showed similar behavior through the tidal cycle. The gradient Richardson numbers at the pycnocline indicate that the water column remains stratified throughout the tidal cycle at station 1 . At stations 2-6 the evolution of stratification in the water column appears to be associated with advection of the salt wedge. Smaller gradient Richardson numbers at the beginning of flood and late ebb are associated with the head of the salt wedge; higher values are associated with the region after the head. This spatial pattern of the gradient and bulk Richardson numbers is presented for the transect measurements (Fig. 7). The gradient and bulk Richardson numbers suggest that the flow remains stable throughout the tidal cycle and that turbulent mixing tends to be suppressed at the pycnocline. Moreover, the gradient Richardson numbers were generally low $(\mathrm{Ri}<0.25)$ below the pycnocline, indicating instability of the region near the bed due to bed-generated turbulent mixing.

To elucidate the role of advection and turbulent mixing on the evolution of the pycnocline height, turbulent viscosity and diffusivity profiles at stations 1 and 2 are presented, in Fig. 8, together with estimates for the three terms in the salt conservation equation, in Fig. 9. Figures $8 \mathrm{a}, \mathrm{c}$ shows how the pycnocline position in the water column controls the distribution of the turbulent viscosity and diffusivity at station 1 . The height of the pycnocline above the bed and the maximum turbulent diffusivity values above the bed decrease during ebb, and vice versa during flood, due to downestuary and upestuary advection of the salt wedge by the tide, respectively. At station 2 (Figs. 8b,d) the effects of stratification on the vertical distribution of the diffusivity profiles are less pronounced 

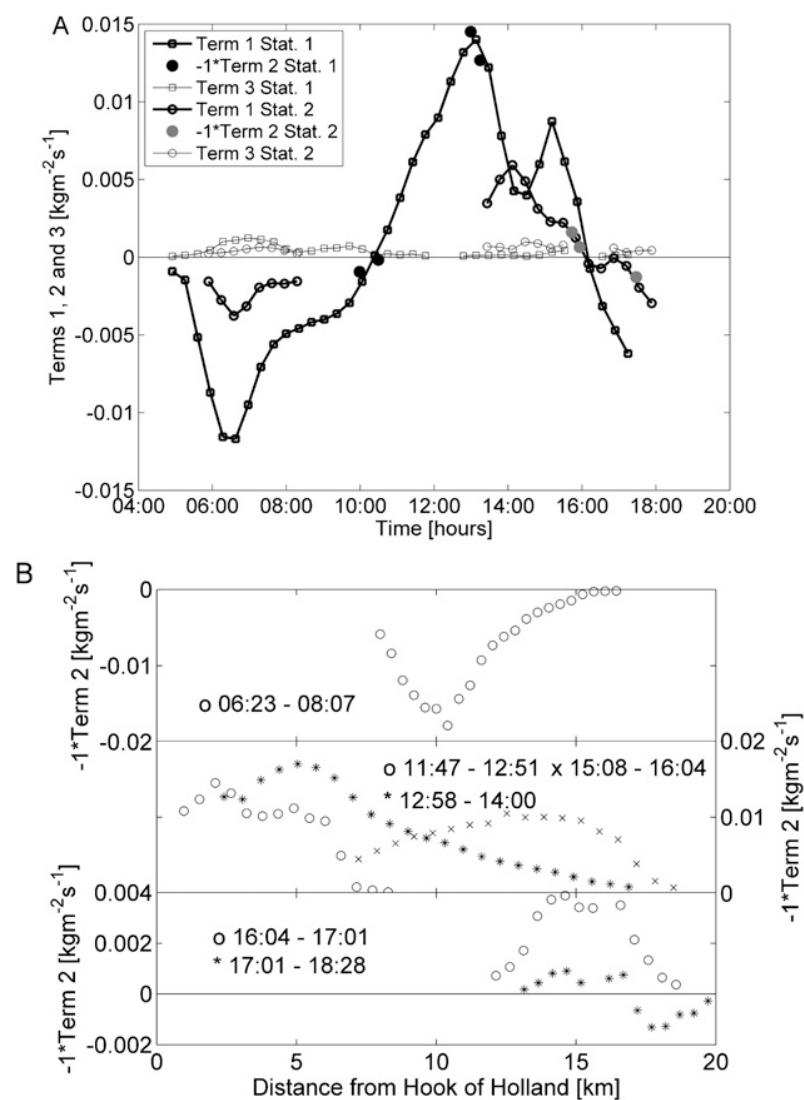

FIG. 9. (a) Graph of time series of terms 1 and 3 [see Eq. (5)] at stations 1 and 2 and term 2 estimated from the transect measurements within $500 \mathrm{~m}$ of stations 1 and 2. (b) Graph of the alongchannel distribution of term 2 at selected times. The beginning and end time of each transect are indicated in the panels.

during ebb than during flood. This appears to be an artifact of the small density gradient (see the 1-2-psu contour of Fig. 2). The calculated turbulent viscosity profiles do show a trend of distinctly lower values above the pycnocline, as observed in Figs. 8a,c.

The observations suggest that the pycnocline controls the bottom boundary layer height. Therefore, it is likely that the growth of the boundary layer is related to the growth of the pycnocline height above bed, and vice versa. We analyze the contribution of advection and turbulent mixing to the growth rate of the pycnocline height from the conservation equation of salt integrated over the pycnocline height. Figures 9a,b show terms 1, 2, and 3 of Eq. (5) at stations 1 and 2. Term 2 (in Fig. 9a) has been determined from the transect measurements within $500 \mathrm{~m}$ of stations 1 and 2 . The dataset is not complete at the fixed stations 1 and 2 (Fig. 9a) but, together with the estimates of term 2 from the transect measurements (Fig. 9b), it suggests that advection effects (term 2) determine the local rate of change (term 1),

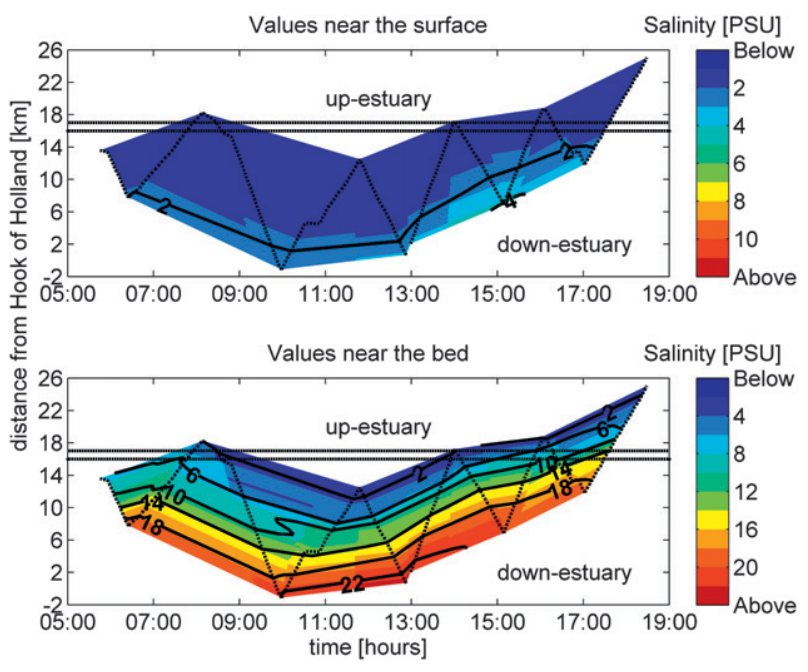

FIG. 10. Along-channel distribution of salinity in (top) a nearsurface layer and (bottom) a near-bed layer during the survey on 11 Apr 2006. The dashed lines in both graphs depict, from bottom to top, the Botlek Harbor and the Rotterdam Waterway-New Meuse-Old Meuse junction. The dashed dotted lines in both graphs depict the navigated transects.

particularly during ebb and flood advection periods. Compare Fig. 9a term 1 between 05:00 and 08:00 h (station 1) with Fig. 9b (top) and term 1 between 11:00 and 16:00 h (stations 1 and 2) with Fig. 9b (middle and bottom). Near slack water the three terms can become of similar order of magnitude (station 1 around 10:30 h).

\section{$b$. The evolution of velocity and salinity in a frame of reference moving with the salt wedge}

Figures 10 and 11 present the evolution of the nearsurface and near-bed salinity and velocity in a frame of reference moving with the salt wedge. Figure 10 shows the strong vertical stratification between the surface and near-bed layer with differences of about 22 psu near the mouth, as well as the upstream limit of salt intrusion where the differences go to zero. It also highlights the strong along-channel gradient of salinity in the lower layer. The zero velocity contour (in bold) in Fig. 11 depicts slack water. This contour highlights the presence of exchange flows and shows distinct phase lags between the occurrence of slack water in the upper and lower parts of the water column, both around low water slack (LWS) (10:00-12:00 h) and high water slack (HWS) (16:00-18:00 h). These time lags are also evident in Fig. 2 at station 1 at LWS and at stations 2, 3, and 5 at HWS.

\section{c. Tidal wave propagation and tidal flow characteristics}

To understand how the tide progresses up the Rotterdam Waterway and how its characteristics change, a detailed 


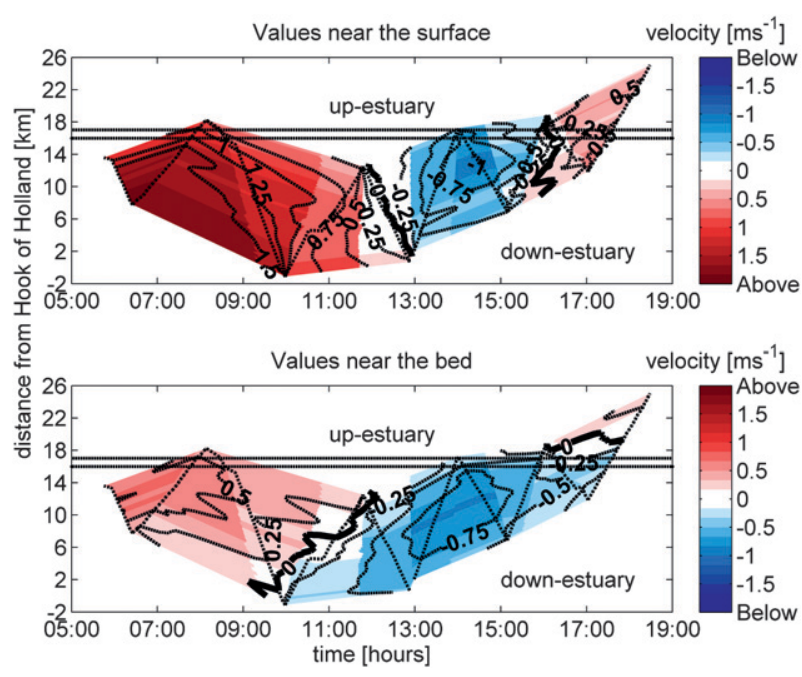

FIG. 11. Along-channel distribution of the primary (along channel) velocity component (negative $=$ flood) in (top) a nearsurface layer and (bottom) a near-bed layer recorded during the survey on 11 Apr 2006. The dashed lines in both graphs depict, from bottom to top, the Botlek Harbor and the Rotterdam Waterway-New Meuse-Old Meuse junction. The dashed dotted lines in both graphs depict the navigated transects.

analysis of the propagation of the tidal wave has been carried out. The results of this analysis are summarized in Tables 3 and 4. HWS and LWS are expected to start later farther upstream with respect to Hook of Holland. However, the timing of LWS and HWS (Table 3, columns 2 and 3) show a different trend. Harmonic analysis indicates that, when the tidal wave progresses upestuary, it has characteristics of both progressive and standing waves (Table 4, see the second column, last two rows). This shift in tidal wave characteristics is ascribed to the large number of harbor basins located on the New Meuse.

The results in Table 4 (row 2, columns 3-6) show that the tidal wave is already deformed when it enters the Rotterdam Waterway. This deformation is due to the shallowness and interaction with topography and geometry in the coastal zone. Table 3 further shows that the $M_{4 ; \zeta}\left(M_{2 ; \zeta}\right)^{-1}$ amplitude ( $\zeta$ : water level, $U$ : velocity) ratios do not significantly increase farther upestuary (see columns 3-6 and Fig. 12, stations 1, 2, 5, and 7). This indicates that, in this part of the estuary, the effect of nonlinear shallow water interactions on the generation of the $M_{4}$ overtides is small. Hence, the tide in the coastal zone determines most of the $M_{4}$ overtide structure (water level and velocity amplitudes).

The phase differences between the $M_{2}$ and $M_{4}$ water levels $\left(\Delta \varphi_{\zeta}=2 \varphi_{M_{2}}-\varphi_{M_{4}}\right.$; see column 3$)$ are $0^{\circ}<\Delta \varphi_{\zeta}<$ $180^{\circ}$, which indicates that the tide rises faster than it falls. Consequently, this barotropic tidal asymmetry $\left(\Delta \varphi_{U}=2 \varphi_{M_{2}}-\varphi_{M_{4}}\right.$ are $-90^{\circ}<\Delta \varphi_{U}<90^{\circ}$; see column
4 and Fig. 12, stations 1, 2, 5, and 7) combined with the effect of the regulated freshwater discharge (Fig. $12 M_{0}$ velocities) causes larger ebb than flood periods (Fig. 3; see also Table 3, columns 6 and 7).

Upestuary (station 7, Fig. 2), the ebb period and maximal ebb velocity are larger than the flood period and flood maximal velocity (Table 3, last row in columns 5, 6, 7 , and 8), which indicates that the effect of the freshwater discharge dominates over the effects induced by the barotropic tidal asymmetry. The measurements at station 1 , however, show that ebb dominance occurs in the upper part of the water column, whereas flood dominance occurs in the lower part. Furthermore, a relatively long period of low near-bed ebb velocities and a long LWS period (Table 3) are observed. This is ascribed to the characteristic time development of the barotropic pressure gradient around LWS (double LW).

\section{d. Harmonic analysis of internal currents}

To understand the role of internal tidal asymmetry on the tidal current structure a harmonic analysis has been carried out on time series of velocity profiles. Figure 12 shows that in the freshwater-saltwater mixing region (stations 1,2, and 5) the variation of the $M_{2}, M_{4}$ phases in the vertical are larger then in the freshwater region (station 7). This variation depicts small contributions by internal baroclinic effects. However, $180^{\circ}$ phase shifts in the vertical of the $M_{4}$ phases are not observed. Furthermore, the normalized overtide current amplitudes (see section 2c) are approximately between 1 and 2 (Fig. 12, stations 1, 2, and 5, and Table 4, column 7). These are typical values when internally driven nonlinearities are small or do not occur. Jay and Musiak (1996) report values for this parameter ranging from 3 to 12 . Furthermore, in the Rotterdam Waterway the ratios of $M_{4 ; \zeta}\left(M_{2 ; \zeta}\right)^{-1}=0.24$ (station 1) and 0.21 (station 2). These values are about 10 times larger than found for the Columbia River, which confirms the dominance of the barotropic tidal asymmetry.

The character of this asymmetry is such that the time period between maximal ebb and flood velocities is not exactly half a tidal cycle, as assumed in the theoretical model by Jay (1991) and Jay and Musiak (1996). Furthermore, the observation of maximum velocities at the pycnocline (Fig. 2, station 1, 12:00-15:00 h) indicates that the assumption of monotonically increasing velocities from the bed to the free surface is also violated. In fact, the baroclinic pressure gradient may also show anharmonic variation at a particular station. For instance, calculations from measurements presented in Fig. 5 indicate that maximum longitudinal density and, hence baroclinic pressure, gradients occur roughly halfway along the salt wedge and decrease landward and seaward from this 
point (not shown). The barotropic forcing is not perfectly cyclic over a semidiurnal tidal cycle due to the diurnal inequality (section 3a). Consequently, the asymmetrical tidal excursion of this along-channel distribution may cause a complex variation of these gradients with time at some stations (Figs. 2 and 5). This is the case, in particular, when part of the along-channel saltwater distribution is affected by exchange with the harbor basins and junctions (de Nijs et al. 2008, 2009). The development of the isohalines also suggests some contributions by lateral advection due to secondary circulations (e.g., Uncles 2002; Lerczak and Geyer 2004), though their precise role cannot be adequately evaluated from the measurements. Jay (1991) indicated that (nontidal) secondary circulations can also contribute to the observation of anharmonicity in the $M_{4}$ frequency band.

The time-varying contribution of the baroclinic structure to the tidal current field may also be deduced from the velocity profiles at station 1 . The time period that an exchange-type flow structure is observed is larger near LWS than at HWS. This observation can be attributed to a decrease of $\partial \rho / \partial x$ at the end of flood, compared to ebb, because the saltwater interface is higher at the end of flood $\left[D^{-1} \int_{D} \rho_{0}^{-1} \partial \rho / \partial x d z\right.$ (Fig. 2, station 1)]. However, advection may complicate this interpretation because it may oppose seaward acceleration of the flow above the salt wedge and, therefore, obscure the identification of exchange flow profiles at HWS and vice versa at LWS. It is further noted that near HWS the opposing barotropic pressure gradients are larger than at LWS.

\section{e. Momentum balance and mechanistic overview}

Although the barotropic and baroclinic pressure gradient terms in the momentum balance are dominant, it is also evident that advection plays a key role in the evolution of the salt wedge, Fig. 13. The advection of the salt wedge is modulated by the barotropic asymmetry imposed at the mouth. The result of the combined $M_{2}$ and $M_{4}$ tidal signal is visible in the time series of the horizontal velocity profiles (Figs. 2 and 3). For instance, there is a double LW due to the phase difference between the $M_{2}$ and $M_{4}$ component (Fig. 3). The influence of the barotropic tidal forcing is evident in the transects (Fig. 5) and in the momentum balance; note the barotropic pressure gradient terms in Fig. 13. It imposes a time scale on the advection of the salt wedge. Therefore, the $M_{4}$ tidal constituent is an important time scale in the time development of mean flow and turbulence properties. Advection of momentum will influence the resulting shape of the velocity profiles, as it determines the velocity shear and thus the strength of the differential advection and mixing.
During LWS pronounced advection maxima are observed in the pycnocline (Fig. 13, transect 3). Advection in the pycnocline and in the upper water column acts with the ebb-directed barotropic pressure gradient. During flood, pronounced advection minima over the vertical are observed in the pycnocline, which favors acceleration of the flow in the upestuary direction (transect 6), while, during ebb, maxima over the vertical occur in this region (not shown), which accelerates the flow. During HWS advection opposes seaward acceleration of the flow above the salt wedge (transect 9). Therefore, advection above the salt wedge obscures the identification of exchange flow profiles at HWS and favors it at LWS. This process is more distinct downestuary (i.e., LWS) since the effects of cross-sectional changes on momentum advection are more marked upestuary.

The competition between the baroclinic and barotropic pressure gradient is further examined from Fig. 13. The role of baroclinicity leads to the lengthening of the flood period relative to the ebb period in the lower part of the water column, and vice versa in the upper part. This is observed at station 1 at LWS (see Fig. 2, 10:00-12:00 $\mathrm{h}$ ) and at stations 2, 3, and 5 at HWS (16:0018:00 h; see Table 3, columns 6 and 7). Furthermore, these exchange flow profiles advance (delay) the onset of ebb (flood) in the upper part of the water column and delay (advance) the onset of ebb (flood) in the lower part (Table 3) in the area of salt intrusion. Near LWS the balance between the opposing baroclinic and barotropic pressure gradient acceleration shifts over the vertical; in the near-bed region (Fig. 13, transect 3) this drives the observed flood current near the bed against the ebb current (transect 3, Fig. 5). This behavior is also observed at station 1 in Figs. 2 and 11. Around HWS the baroclinic pressure gradient maintains a balance against the reversing barotropic gradient near the bed (Fig. 13, transect 9) that sustains a near-bed flood current, while landward of the salt wedge the current is ebbing (Fig. 5, transects 8-10). This behavior is also observed in Fig. 2 at stations 2, 3, and 5 and in Fig. 11. Furthermore, it is evident that the double LW affects the shift in the vertical balance between the baroclinic and barotropic pressure gradients, leading to a distinctly longer LWS period near the bed at station 1 (Table 3). Hence, it affects the development of exchange flow profiles.

The shear recorded in transects 3 and 4 (Fig. 5) is mainly due to the baroclinic gradient, which opposes the (barotropic) near-bed ebb flow (Fig. 13), bed friction, and a reduction of turbulent mixing above the pycnocline. The latter intensifies the ebb velocities in the upper layer relative to the lower layer. At this phase of the tide the variation of isohalines therefore appears to be mainly controlled by seaward advection of fresh (brackish) 


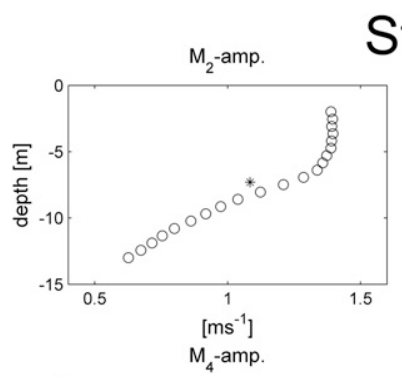

Stn. 1
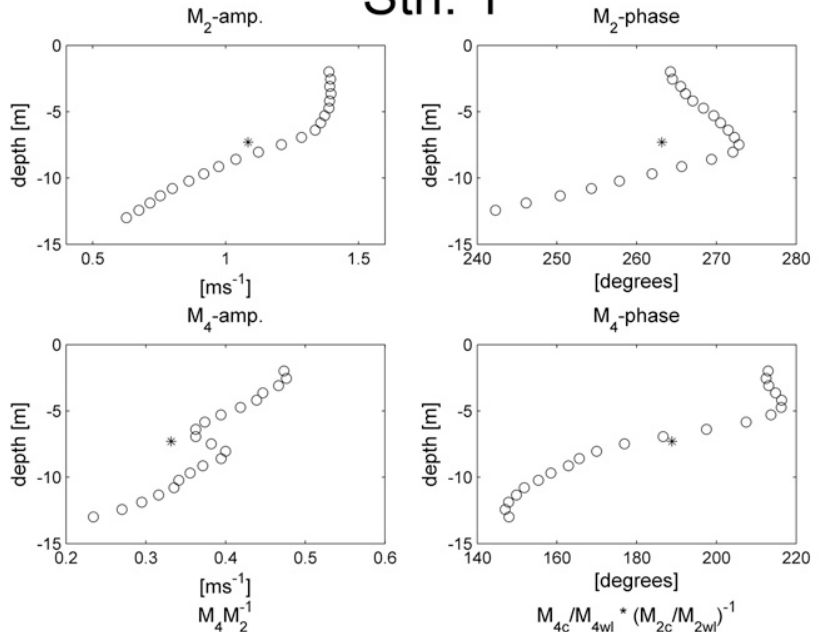

$\mathrm{M}_{4 \mathrm{c}} / \mathrm{M}_{4 \mathrm{wl}}{ }^{*}\left(\mathrm{M}_{2 \mathrm{c}} / \mathrm{M}_{2 \mathrm{wl}}\right)^{-1}$
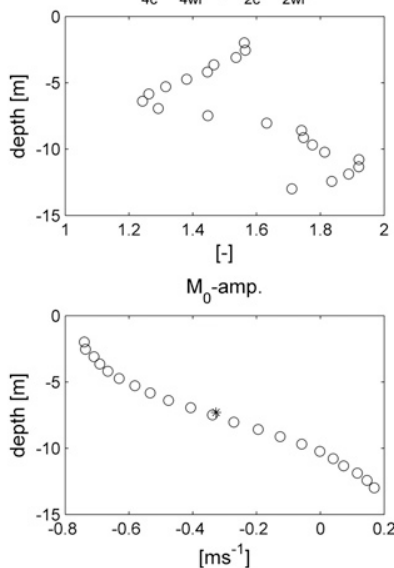

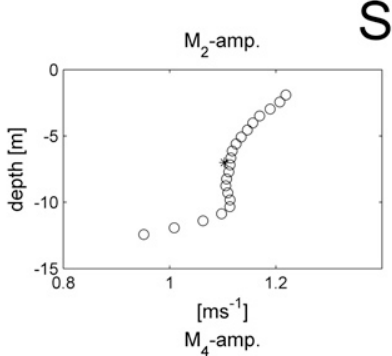

Stn. 2 Miphase
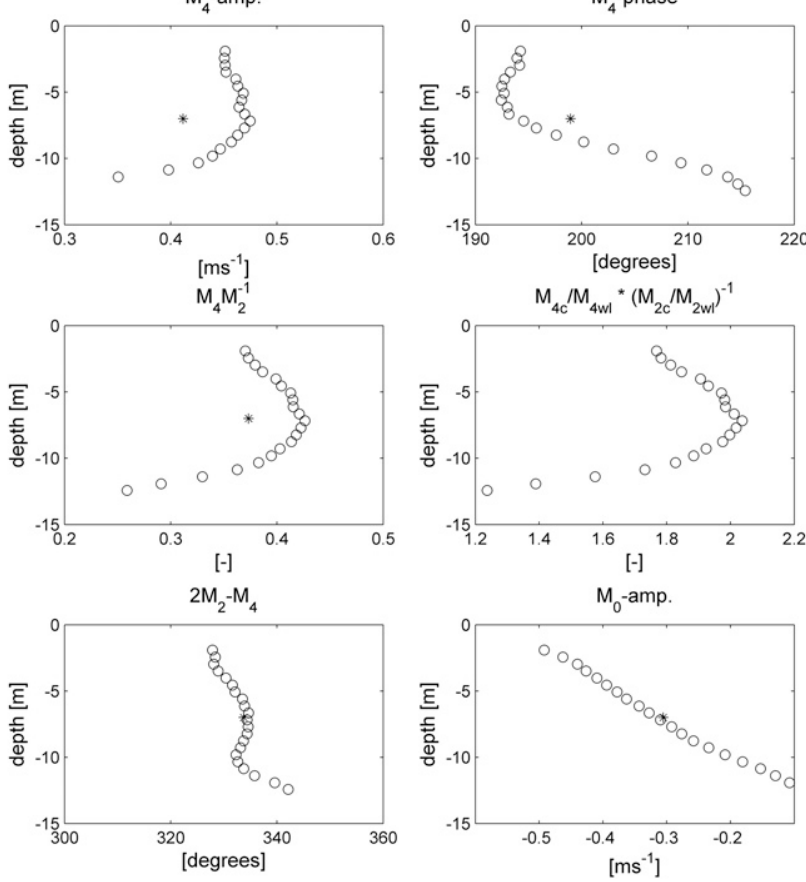

FIG. 12. Four groups of graphs are presented that show the tidal properties at stations (top left) 1, (top right) 2, (bottom left) 5, and (bottom right) 7. The graphs show the results of the harmonic analysis of the vertical distribution of the horizontal current structure. Each station subplot presents the respective $M_{2}$ amplitude and phase, $M_{4}$ amplitude and phase, ratio $M_{4}\left(M_{2}\right)^{-1}$ amplitudes, relative amplitude ratio (methods section; Jay 1991; Jay and Musiak 1996), relative phase $\left(2 \varphi_{M_{2}}-\varphi_{M_{4}}\right)$ and $M_{0}$ component.

waters over salty waters and possibly a small contribution by upstream advection of saltier water near the bed.

\section{f. Decoupling effects and evolution of jetlike features}

During flood tide velocity maxima at middepth are observed, see Fig. 2 (station 1, 12:00-15:00 h) and Fig. 14 (station 1), which suggests strong internal shear. This phenomenon has also been observed in the Fraser River (Geyer and Farmer 1989) and more recently in the Hudson River (Chant et al. 2007). The transect measurements show that these maximal velocities coincide with the pycnocline (Fig. 5, transects 5 to 8 ). These regions extend throughout the Rotterdam Waterway and persist (some distance behind the head of the salt wedge) until HWS occurs in the upper part of the water column (transect 8). The time series of velocity profiles at station 1 (Fig. 2) shows that, from their onset to about the first half of flood, maximum velocities shifted approximately from the near bed to the middepth part of the water column. This temporal development corresponds with the flood tidal excursion of the salt wedge structure into the Rotterdam Waterway. The baroclinic driving force increases with depth; hence, in the pycnocline, the alongchannel pressure gradient is larger than in the upper part of the water column. Salt stratification decouples the brackish and saltwater layers. Consequently, turbulence levels in the pycnocline are less than in the lower part of the water column. The velocity measurements at station 1 (Fig. 2) indicate that the pycnocline position regulates the extent to which turbulence-induced frictional effects can protrude into the water column (Fig. 8).

\section{Discussion}

This observational study provides insight into the physical mechanisms controlling the internal flow structure 


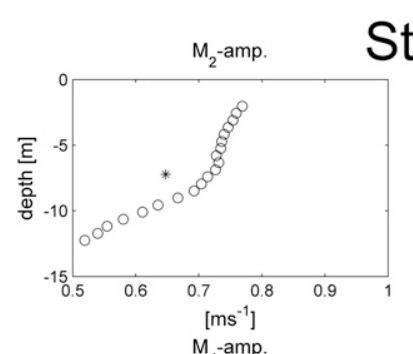

Stn. $5 \quad M_{2}$-phase
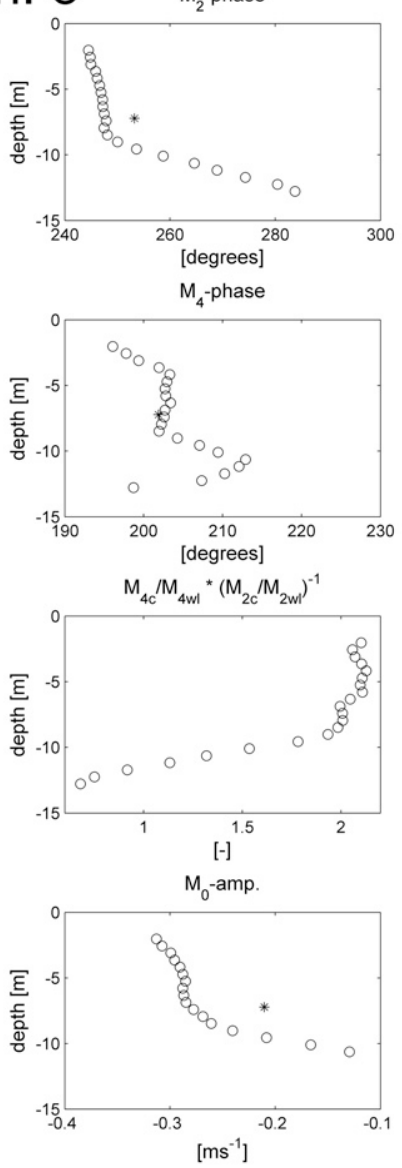

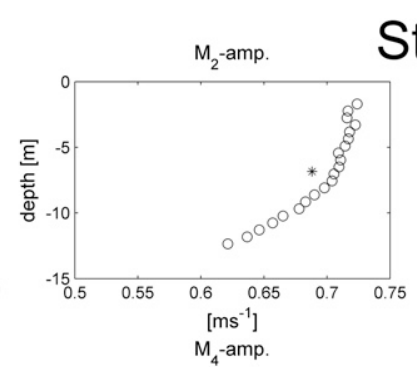

Stn. 7

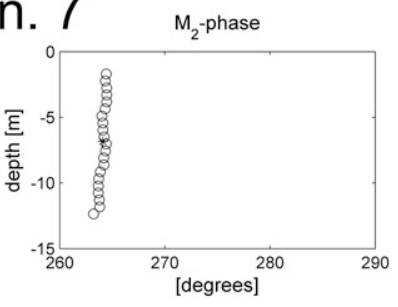

$\mathrm{M}_{4}$-phase
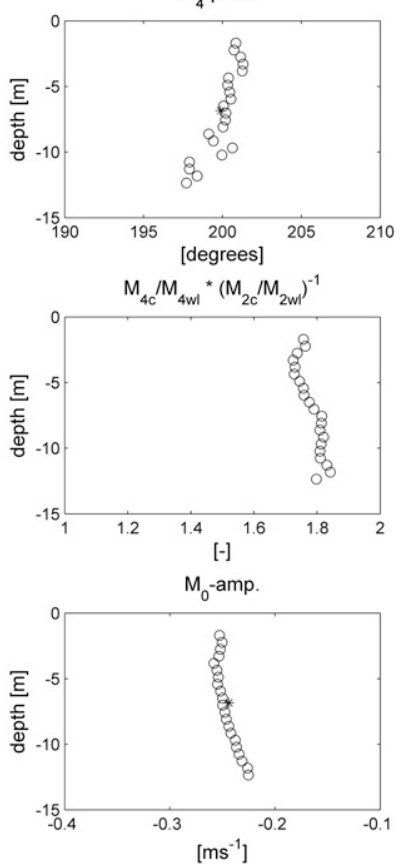

FIG. 12. (Continued)

within a partially and/or stratified estuary to a shallow shelf sea, the Rotterdam Waterway. In common with many other estuaries bordering shallow shelf seas, barotropic tidal asymmetry arises within the shallow shelf sea due to nonlinearities that cause the tidal wave to be deformed before entering the estuary. Consequently, barotropic asymmetry can impose a time scale at the mouth of the estuary that induces an asymmetry between ebb and flood that can influence subsequent evolution of the flow within the estuary.

In the Rotterdam Waterway this results in the evolution of a different internal flow response within the estuary than that observed in the Columbia River and as described in classical internal tidal asymmetry literature. Contrary to the idealized model by Jay (1991) and Jay and Musiak (1996), the barotropic structure determines the $M_{4}$ tidal constituent frequency band. The generation of shallow water nonlinearities within the estuary interior itself is small. In contrast to internal tidal asymmetry, barotropic asymmetry at the mouth governs the advection of the salt wedge and therefore influences the subsequent evolution of apparent asymmetries in the internal flow structure, as observed in Figs. 2, 5, 11, 12, and 14.

Jay (1991) and Jay and Musiak (1996) found a less distinct barotropic $M_{4 ; U}$ component near the mouth of the Columbia River and that significant internal overtides in the $M_{4 ; U}$ frequency band evolved within the Columbia River. This is most likely a consequence of the deep and narrow shelf offshore, which does not allow barotropic asymmetry to evolve at the mouth. However, the long narrow, funnel-shaped, estuary does generate nonlinearities within the estuary. In contrast, in the Rotterdam Waterway the $M_{4}$ overtide structure is externally forced at the mouth of the estuary and generation of the $M_{4}$ overtides within the estuary is relatively small. This can be explained by the absence of intertidal areas, the approximately constant prismatic cross sections, and the relatively small ratio of water level amplitude to water depth $\left[\zeta(H)^{-1} \approx 0.11\right]$.

Geyer (1993) discussed the role of a collapse of turbulence at the head of the salt wedge. If one applies his arguments to a stratified estuary, forced by barotropic 
Transect 3
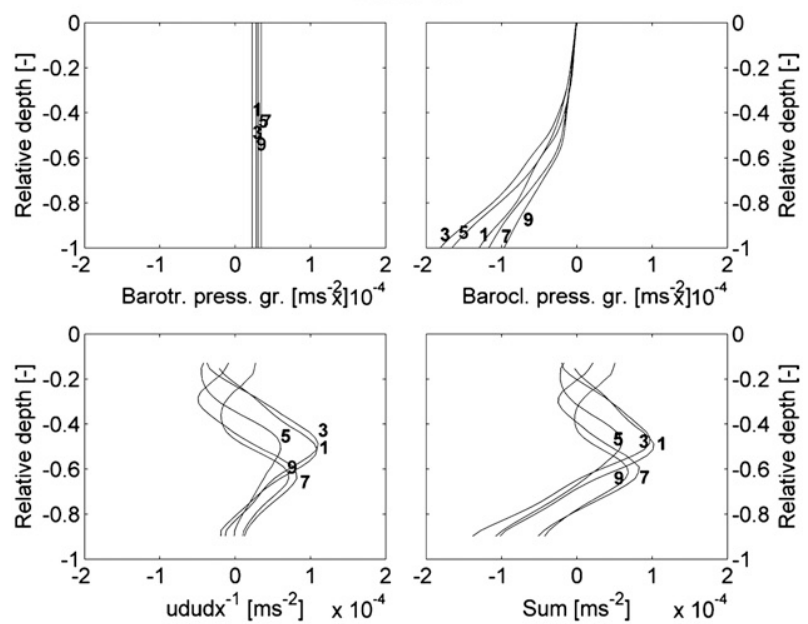

Transect 6
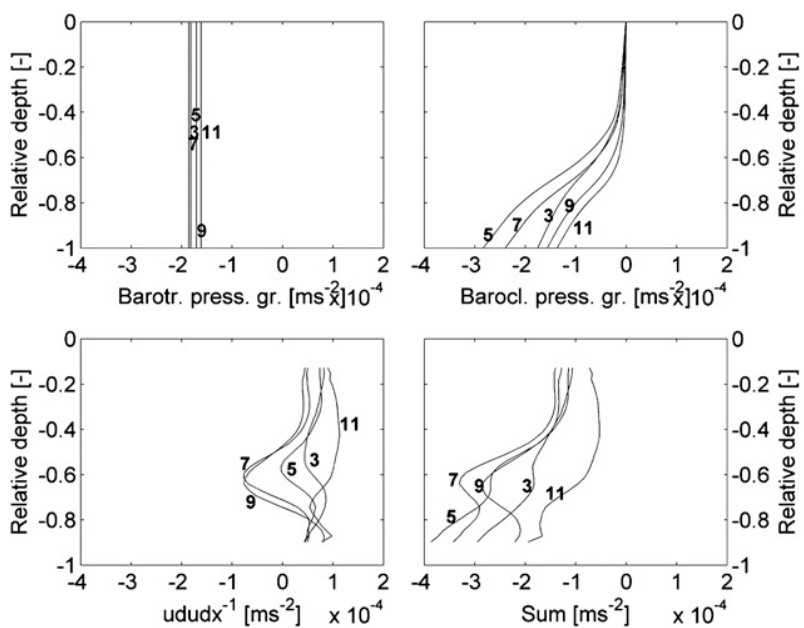

Transect 9
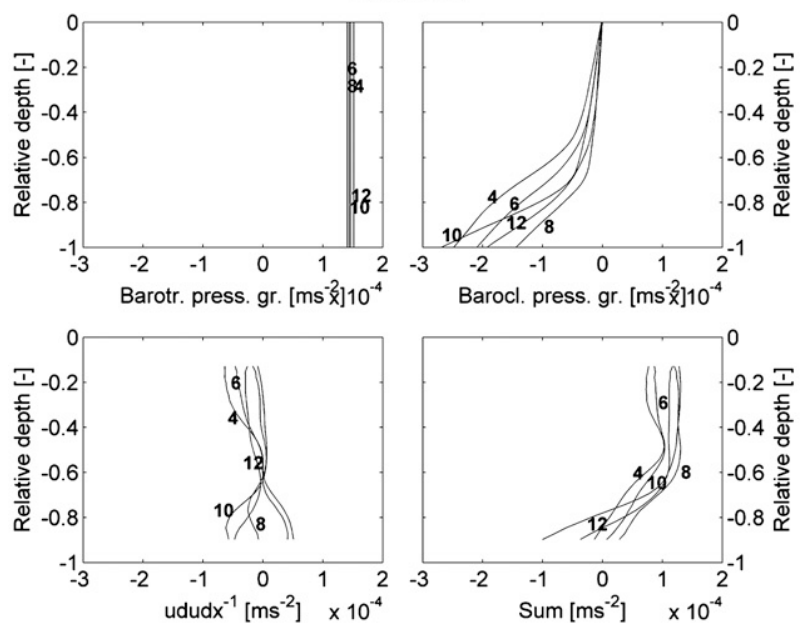

FIG. 13. Data from transects (top) 3 (about LWS), (middle) 6 (flood), and (bottom) 9 (about HWS) have been used to estimate terms in the momentum balance. The graphs for each transect are (top left) the vertical distribution of the barotropic pressuregradient-induced acceleration $\left(\mathrm{m} \mathrm{s}^{-2}\right)$; (top right) the baroclinic asymmetry at the mouth, the resulting turbulent flow structure can be schematized as in Fig. 15. Barotropic tidal advection of the salt wedge in combination with the suppression of turbulence at the pycnocline results in the formation of exchange flows driven by the along-channel baroclinic pressure gradient, as well as the formation of middepth jets. Consequently, Fig. 15 shows how the internal flow structure evolves and feeds back on the external tidal velocity structure in the Rotterdam Waterway. This results in ebb - flood differences that are distinct from internal tidal asymmetry, as described by Jay (1991). Furthermore, in contrast to the theory of internal tidal asymmetry, tidal asymmetries in turbulent mixing, stratification, and pycnocline height develop in the Rotterdam Waterway as the result of barotropically driven asymmetries in ebb-flood currents and associated displacements of the salt wedge.

Exchange flow profiles are more apparent at LWS or HWS at fixed stations (cf. Fig. 2 with Fig. 15), and the internal structure measured by successive passages through the head of the salt wedge (Fig. 11) is more distinct than measured at the fixed stations (Fig. 2) because baroclinic gradients are generally larger at the head. The vertical distribution of the along-channel velocity around slack water, at the limit of saltwater intrusion, may be viewed as a baroclinically driven exchange-type flow superimposed on the barotropically driven reversing tidal flow (Figs. 2, 10, 11). The development of exchange flows indicates differential advection between the upper freshwater and lower saltwater layers and convergence of near-bed flows. These exchange flows are determined by a vertical shift in the balance between the baroclinic and barotropic pressure gradients, though advection is not negligible (Fig. 13). Baroclinic effects retard flow reversal near the bed and enhance this reversal near the surface, leading to convergence of near-bed flows and some divergence in the upper part of the water column (Table 3, stations 5 and 7; Fig. 5, transect 9; and Fig. 11, 16:00 h).

The occurrence of maximal velocities at the pycnocline (Fig. 2, station 1; Fig. 5, transects 6 to 9; and Fig. 14) indicate a decoupling of the brackish and saltwater layers due to turbulence damping and also suggest that interfacial stress is negligible. This is in agreement with estimates of turbulent viscosity profiles following the

\footnotetext{
$\leftarrow$

pressure-gradient-induced acceleration; (bottom left) the advective inertia-induced acceleration; and (bottom right) the sum of the barotropic, baroclinic, and advective inertia accelerations. The profiles have been numbered upstream from the sea boundary.
} 

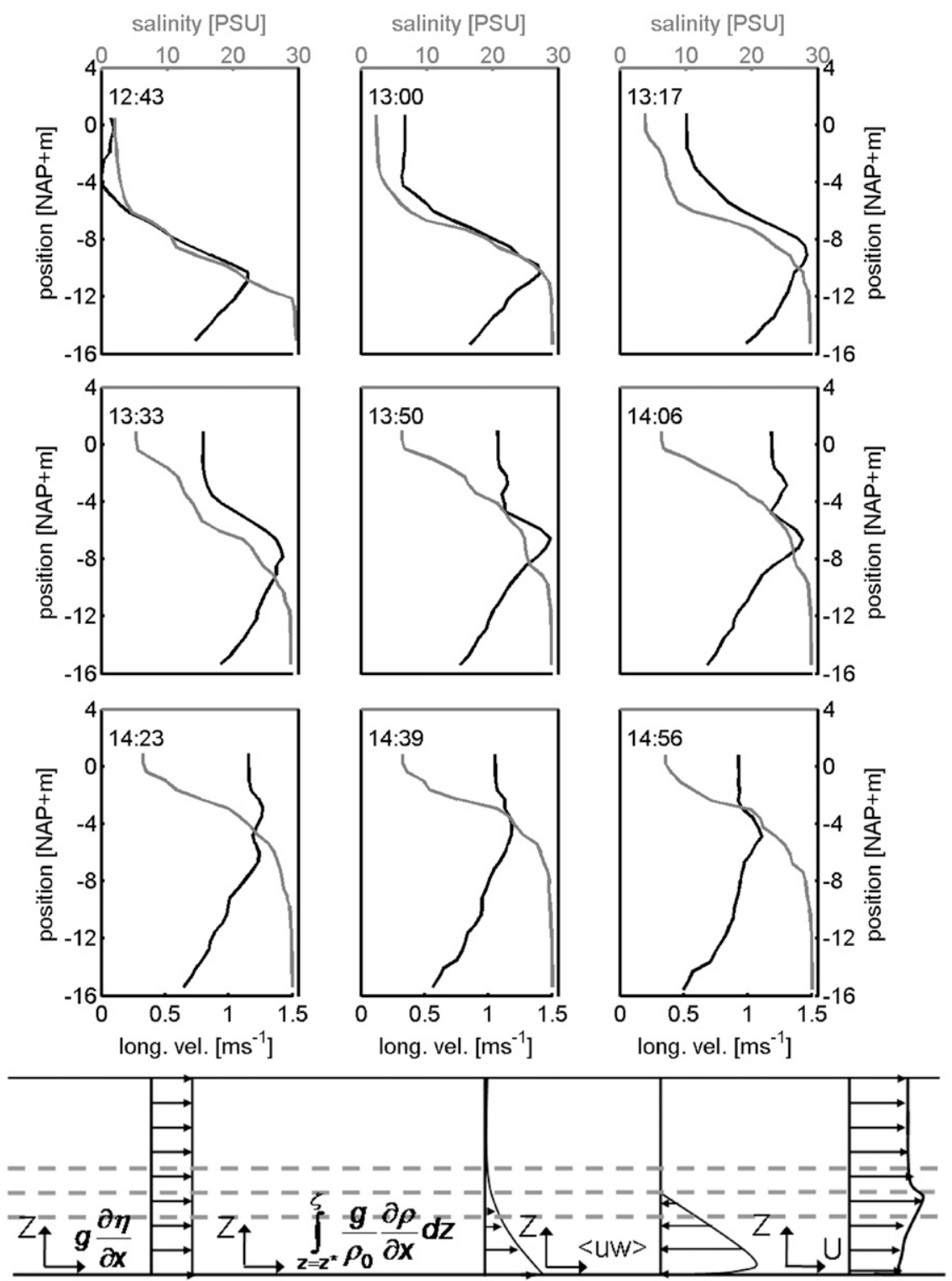

FIG. 14. Profiles of salinity (gray) and longitudinal velocity (black) at station 1 during the first half of flood. The time in hours is indicated in the top left of the graphs. The graphs show that the tidal displacement of the salt wedge into the Rotterdam Waterway determines the height of the pycnocline above the bed. The shift of the maximal velocities higher into the water column with time indicates that the pycnocline regulates the extent to which bed-generated turbulent mixing can protrude into the water column. (bottom) A schematic showing the dominant terms in the momentum balance and how they contribute to the formation of the observed middepth jets at the pycnocline (from left-right): the barotropic pressure-gradient-induced acceleration, the baroclinic pressure gradient-induced acceleration, the vertical turbulent transport of momentum $\langle u w\rangle$, and the resultant velocity profile. The schematic shows that, in the region of the salt wedge, the bed-generated turbulence $\langle u w\rangle$ is confined below the pycnocline. This leads to decoupling effects and the formation of the middepth jets as recorded on the flood tide.

same method as described in Geyer et al. (2000) and their corresponding buoyancy flux estimates (Figs. 8 and 9). This internal shear on flood (Figs. 2, 5) results in advective transport from the pycnocline toward regions of lower momentum and salinity (Figs. 13, 14).
The results of this study are in agreement with those by Geyer et al. of the Hudson River, a partially mixed estuary, that interfacial turbulence is less important than turbulence generated at the bed. They showed that the estuarine circulation is primarily controlled by the bed 


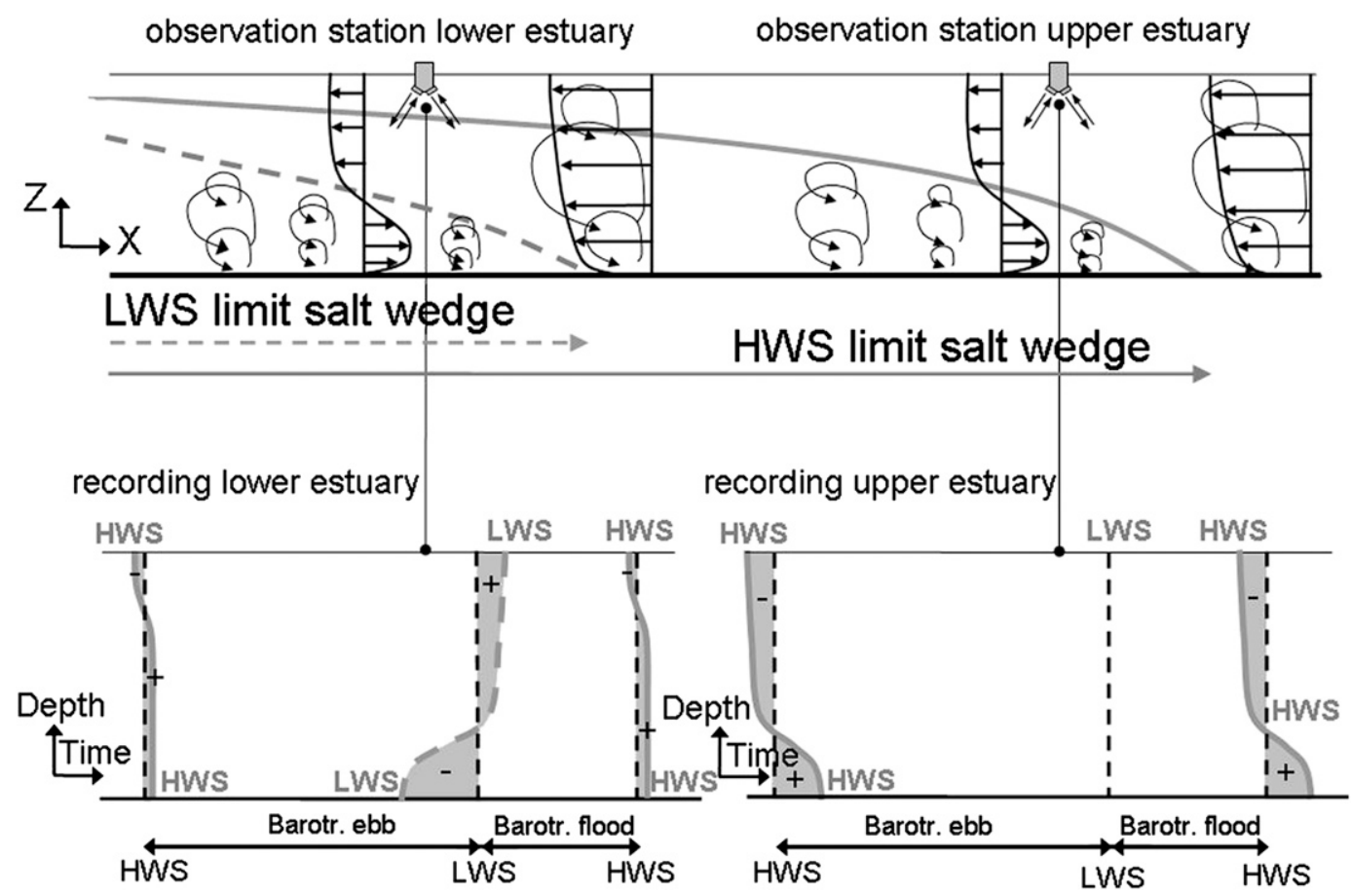

FIG. 15. A summary sketch of the relationship between the tidal advection of the salt wedge and the evolution of the internal baroclinic structure in the Rotterdam Waterway. (top) Highlighted is the tidal advection of the salt wedge. The gray lines show the location of the salt wedge at low water slack (LWS) (dashed) and high water slack (HWS) (solid). The exchange flow profiles at the tip of the salt wedge are evident, as are the seaward-velocity profiles directed seaward upstream of the salt wedge. Two observation stations are included at the approximate location of the salt wedge at LWS and at HWS. (bottom) The corresponding time evolution of the velocity profiles as would be recorded during a tidal cycle at the two observation stations. Contour plots show the vertical structure of the horizontal velocity through time, in which only the zero-velocity contour has been drawn as a slack water indicator. The black dashed lines depict barotropic slack water. Barotropic tidal asymmetry at the mouth imposes the observed asymmetry in the length of the ebb and flood periods (periods between dashed black lines). The gray dashed and continuous lines depict baroclinic slack water at the two different locations. The internal structure is related to the tidal advection of the salt wedge. The gray areas bordered by the gray dashed and continuous lines show how baroclinically driven exchange flows advance and postpone barotropic slack water. Hence, these exchange flows lengthen the flood in the lower part and lengthen the ebb in the higher part of the water column. Note that Figs. 2, 3, 5, 11, and 14 show the effects of baroclinic shear flows on the vertical velocity structure.

stress acting on the lower layer. It can be deduced from the velocity measurements (Fig. 2, stations 1 and 2) and the general observation of low $\mathrm{Ri}(<0.25)$ in the region near the bed (Fig. 6) that bed-generated turbulence is mainly confined to the region below the pycnocline. Richardson numbers at the pycnocline are larger on flood than on ebb because of the higher shear around middepth during ebb than flood (Figs. 6 and 7). The Ri and $\mathrm{Ri}_{B}$ obtained from fixed station and transect measurements (Figs. 6 and 7) generally show values $>0.25$; values $<0.25$ are associated with the area directly at the head of the salt wedge. This indicates that, while mixing is possible at the tip of the salt wedge, advection most likely controls the change of the vertical salinity structure at a particular location (Figs. 8 and 9). Longitudinal advection processes include differential straining, advection by a depth-mean current, and middepth free shear layers. Figure 15 indicates that barotropic advection of the salt wedge dominates over classical tidal straining in determining the time variation of the potential energy anomaly. It should therefore be noted that Eulerian tidal asymmetries in stratification, turbulent mixing, and pycnocline height are not only the result of straining processes (e.g., Simpson et al. 1990) but are also due to asymmetric advection by the depth-mean current of an along-channel distribution. Hence, asymmetric barotropic displacements can cause fluctuations in the turbulence, scalar, and velocity field at a near-bed mooring that can be mistakenly perceived as the result of asymmetries in turbulent mixing.

Interestingly, the processes that govern the salt wedge structure in the Rotterdam Waterway are different from 
those observed in the Fraser River (Geyer and Farmer 1989; MacDonald and Horner-Devine 2008). Whereas interfacial mixing breaks down the salt wedge on the ebb in the Fraser River, the Rotterdam Waterway remains stratified. We find that a salt wedge structure is displaced $\sim 16 \mathrm{~km}$ back and forth by the tide at the dominant semidiurnal time scale. In the Rotterdam Waterway, the shear across the pycnocline throughout the tidal cycle is weaker and the periods with pronounced exchange-flowtype shear produced by baroclinicity are smaller than in the Fraser River (MacDonald and Horner-Devine 2008). In the Rotterdam Waterway, the latter periods are limited to the periods around slack water instead of a whole tidal cycle. The tidal excursion of the salt wedge is larger and the tidal and spatial mean buoyancy fluxes are one to two orders of a magnitude lower than observed in the Fraser River (MacDonald and Horner-Devine 2008). Hence, advection plays an important role in the salt balance (see also de Nijs et al. 2010).

Jay (1991) questioned the role of the baroclinic pressure gradient in establishing the estuarine circulation, as highlighted in studies by Pritchard (1954), Hansen and Rattray (1965), and Chatwin (1976). He suggests that differences in the intensity of turbulent mixing between flood and ebb would generate internal tidal velocity asymmetry and would provide an important contribution to the estuarine circulation. However, as shown here, internal tidal asymmetry does not play a significant role in the Rotterdam Waterway. The region of significant along-channel baroclinic pressure gradient is more localized and is advected by the tide, as a result of which distinct exchange profiles occur at the downestuary stations at LWS and upestuary station at HWS. The classical estuarine circulation driven by the baroclinic pressure gradient is associated with time-mean shear and stratification correlations. These transport terms are dominant in the salt balance (de Nijs et al. 2010). However, baroclinic shear flows, specifically the exchange flow profiles at slack water, are associated with tidally varying shear and stratification correlations, particularly at the upestuary salt intrusion limit. This has implications for salinity intrusions. Excursions of saltwater are governed not only by baroclinic exchange processes at the mouth but also by baroclinic exchange processes within the estuary interior. It is evident that nonclosing tidal correlations associated with the asymmetrical advection of the salt wedge (see de Nijs et al. 2010) also play a role in the salt balance, particularly at stations located farther upestuary.

The internal flow is closely related to the structure and location of the along-channel distribution of salinity, which can change on a tidal time scale. It can also change on subtidal time scales due to the freshets and the spring-neap cycle (Haas 1977; Jay and Smith 1990). Moreover, adjustment of the along-channel salinity structure to changes of the boundary conditions causes adjustment time-scale effects (Kranenburg 1986; MacCready 1999). Therefore, the intensity of the internal phenomena at a particular site will vary.

We anticipate that the mechanism presented here (Fig. 15) operates in the Rotterdam Waterway throughout the year. The hydrodynamic conditions do no vary significantly; the ratio of neap to spring tidal amplitude (0.6 and $1 \mathrm{~m}$, respectively) amounts to 0.6 , and the river flow is largely controlled to $\sim 1500 \mathrm{~m}^{3} \mathrm{~s}^{-1}$. Furthermore, we believe these mechanisms to be dominant in other partially mixed and stratified estuaries with strong barotropic tidal forcing — such as the Aulne (Allen et al. 1980), Gironde (Allen et al. 1980), Hudson (Nepf and Geyer 1996; Bowen and Geyer 2003), James River (Haas 1977), Mekong estuary (Wolanski et al. 1996), Navesink River (Chant and Stoner 2001), Rappahannock (Haas 1977), Tamar (Uncles and Stephens 1993; Grabemann et al. 1997), Tay estuary (McManus 2005), Tweed (Uncles and Stephens 1996), York River (Lin and Kuo 2003), Weser estuary (Wellershaus 1981; Grabemann et al. 1997), and Winyah Bay (Patchineelam and Kjerfve 2004), - all located on broad shallow shelves or connected to shallow estuarine systems. We find that the simple mechanism presented here accounts for the differences that evolve between a (partially) stratified estuary forced by barotropic asymmetry at its mouth and one in which the tidal asymmetry evolves within the estuary.

Acknowledgments. This research is supported by the Dutch Technology Foundation STW, Applied Science Division of now, and the Technology Program of the Ministry of Economic Affairs. The authors thank the Port of Rotterdam, in particular Herman Meijer, for giving support to this research and for providing vessels and crews to conduct the boat survey. Marc Rotsaert of Port of Rotterdam is also thanked for assistance and support during the startup phase of the survey. The authors also thank RWS Directorate Zuid-Holland, in particular Ad Schipperen and Arie Barendrecht, for providing a vessel and crews for the boat survey. Marc Sas of IMDC Ltd. is gratefully acknowledged for providing instruments and personnel. Royal Boskalis Westminster Ltd. is also thanked for providing a captain for the M.S. Tender. We would also like to thank the EU 6th Framework Programme project European Coastal Sea Operational Observing and Forecasting System (ECOOP) for providing support for the preparation of this paper. We thank two anonymous reviewers for their comments, which substantially improved the paper. 


\section{REFERENCES}

Allen, G. P., J. C. Salomon, P. Bassoullet, Y. Du Penhoat, and C. De Grandpré, 1980: Effects of tides on mixing and suspended sediment transport in macrotidal estuaries. Sediment. Geol., 26, 69-90.

Bowen, M. M., and W. R. Geyer, 2003: Salt transport and the timedependent salt balance of a partially stratified estuary. J. Geophys. Res., 108, 3158, doi:10.1029/2001JC001231.

Burchard, H., and H. Baumert, 1998: The formation of estuarine turbidity maxima due to density effects in the salt wedge. A hydrodynamic process study. J. Phys. Oceanogr., 28, 309-320.

Chant, R. J., and A. W. Stoner, 2001: Particle trapping in a flooddominated estuary. J. Mar. Res., 59, 29-51.

— W. R. Geyer, R. Houghton, E. Hunter, and J. Lerczak, 2007: Estuarine boundary layer mixing processes: Insights from dye experiments. J. Phys. Oceanogr., 37, 1859-1877.

Chatwin, P. C., 1976: Some remarks on the maintenance of the salinity distribution in estuaries. Estuarine Coastal Mar. Sci., 4, $555-566$.

de Nijs, M. A. J., J. C. Winterwerp, and J. D. Pietrzak, 2008: SPM variations in a harbour basin. Proc. Mar. Sci., 9, 357-378.

,$- \ldots$, and — 2009: On harbour siltation in the fresh-salt water mixing region. Cont. Shelf Res., 29, 175-193.

,-- , and -2010 : The effects of the internal flow structure on SPM entrapment in the Rotterdam Waterway. J. Phys. Oceanogr., 40, 2357-2380.

Emery, W. J., and R. E. Thomson, 2001: Data Analysis Methods in Physical Oceanography. Elsevier, 638 pp.

Geyer, W. R., 1993: The importance of suppression of turbulence by stratification on the estuarine turbidity maximum. Estuaries, 16, 113-125.

— namics of a salt wedge. J. Phys. Oceanogr., 19, 1060-1072.

— J. H. Trowbridge, and M. M. Bowen, 2000: The dynamics of a partially mixed estuary. J. Phys. Oceanogr., 30, 20352048.

Godin, G., 1972: The Analysis of Tides. University of Toronto Press, $264 \mathrm{pp}$.

Grabemann, I., R. J. Uncles, G. Krause, and J. A. Stephans, 1997: Behavior of turbidity maxima in the Tamar (UK) and Weser (F.R.G.). Estuarine Coastal Shelf Sci., 45, 235-246.

Haas, L. W., 1977: The effect of the spring-neap cycle tidal cycle on the vertical structure of the James, York, and Rappaphannock Rivers, Virginia, USA. Estuarine Coastal Mar. Sci., 5, 485-496.

Hansen, D. V., and M. Rattray, 1965: Gravitational circulation in straits and estuaries. J. Mar. Res., 23, 104-122.

Jay, D. A., 1991: Internal asymmetry and anharmonicity in estuarine flows. Tidal Hydrodynamics, B. B. Parker, Ed., John Wiley and Sons, 521-543.

—_, and J. D. Smith, 1990: Circulation, density distribution and neap-spring transitions in the Columbia River estuary. Prog. Oceanogr., 25, 81-112.

— flows. J. Geophys. Res., 99, 445-461.

— Origins and consequences. Mixing Processes in Estuaries and Coastal Seas, Geophys. Monogr., Vol. 126, Amer. Geophys. Union, 219-258.

Joyce, T. M., 1989: On in situ "calibration" of shipboard ADCPs. J. Atmos. Oceanic Technol., 6, 169-172.
Kranenburg, C., 1986: A time scale for long-term salt intrusion in well-mixed estuaries. J. Phys. Oceanogr., 16, 1329-1331.

_ layer flow. J. Hydraul. Eng., 115, 1352-1370.

— - _ and G. Abraham, 1991: Trapped internal waves over undular topography. J. Fluid Mech., 226, 205-217.

Lerczak, J. A., and W. R. Geyer, 2004: Modeling the lateral circulation in straight, stratified estuaries. J. Phys. Oceanogr., 34, $1410-1428$.

Li, C., 2002: Axial convergence fronts in a barotropic tidal inletsand shoal inlet, VA. Cont. Shelf Res., 22, 2633-2653.

Lin, J., and A. Y. Kuo, 2003: A model study of turbidity maxima in the York River Estuary, Virginia. Estuaries, 26, 1269 1280 .

MacCready, P., 1999: Estuarine adjustment to changes in river flow and tidal mixing. J. Phys. Oceanogr., 29, 708-726.

MacDonald, D. G., and A. R. Horner-Devine, 2008: Temporal and spatial variability of vertical salt flux in a highly stratified estuary. J. Geophys. Res., 113, C09022, doi:10.1029/2007JC004620.

McManus, J., 2005: Salinity and suspended matter variations in the Tay estuary. Cont. Shelf Res., 25, 729-747.

Miles, J. W., 1961: On the stability of heterogeneous shear flows. J. Fluid Mech., 10, 496-508.

Munk, W. H., and E. R. Anderson, 1948: Notes on the theory of the thermocline. J. Mar. Res., 7, 276-295.

Nepf, H. M., and W. Geyer, 1996: Intratidal variations in stratification and mixing in the Hudson estuary. J. Geophys. Res., 101 (C5), 12 079-12 086.

Officer, C. B., 1976: Physical Oceanography of Estuaries (and Associated Coastal Waters). John Wiley \& Sons, $465 \mathrm{pp}$.

Patchineelam, S. M., and B. Kjerfve, 2004: Suspended sediment variability on seasonal and tidal time scales in the Winyah Bay estuary, South Carolina, USA. Estuarine Coastal Shelf Sci., 59, 307-318.

Pietrzak, J. D., C. Kranenburg, and G. Abraham, 1990: Resonant internal waves in fluid flow. Nature, 344, 844-847.

,,,--- B. Kranenburg, and A. van der Wekken, 1991: Internal wave activity in the Rotterdam Waterway. J. Hydraul. Eng., 117, 738-757.

Pollard, R., and J. Read, 1989: A method for calibration ship mounted acoustic Doppler profilers and the limitations of gyro compasses. J. Atmos. Oceanic Technol., 6, 859-865.

Pritchard, D. W., 1954: A study of the salt balance in a coastal plain estuary. J. Mar. Res., 13, 133-144.

Pugh, D. T., 1987: Tides, Surges and Mean Sea-Level: A Handbook for Engineers and Scientists. Wiley, 486 pp.

Schijf, J. B., and J. C. Schönfeld, 1953: Theoretical considerations on the motion of salt and fresh water. Proc. Minnesota Int. Hydraulics Convention, Minneapolis, MN, IAHR, 321-333.

Sharples, J., J. H. Simpson, and J. M. Brubaker, 1994: Observations and modelling of periodic stratification in the upper York River estuary, Virginia. Estuarine Coastal Shelf Sci., 38, 301-312.

Simpson, J. H., and D. Bowers, 1981: Models of stratification and frontal movement in shelf seas. Deep-Sea Res., 28A, 727-728.

_ in the region of freshwater influence of the Rhine. J. Geophys. Res., 100 (C4), 7037-7044.

_ J. Brown, J. Matthew, and G. Allen, 1990: Tidal straining density currents, and stirring in the control of estuarine stratification. Estuaries, 13, 125-132. 
Stacey, M. T., S. G. Monismith, and J. R. Burau, 1999: Observations of turbulence in a partially stratified estuary. J. Phys. Oceanogr., 29, 1950-1970.

Uncles, R. J., 2002: Estuarine physical processes research: Some recent studies and progress. Estuarine Coastal Shelf Sci., 55, 829-856.

_, and J. A. Stephens, 1993: The freshwater-saltwater interface and its relationship to the turbidity maximum in the Tamar estuary, UK. Estuaries, 16, 126-141.
— , and 1996: Salt intrusion in the Tweed estuary. Estuarine Coastal Shelf Sci., 43, 271-293.

van Veen, J., 1938: Water movements in the Straits of Dover. J. Cons. Int. Explor. Mer, 13, 7-36.

Wellershaus, S., 1981: Turbidity maximum and mud shoaling. Arch. Hydrobiol., 92, 161-198.

Wolanski, E., N. N. Huan, L. T. Dao, N. H. Nhan, and N. N. Thuy, 1996: Fine-sediment dynamics in the Mekong River estuary, Vietnam. Estuarine Coastal Shelf Sci., 43, 565-582. 